\title{
Parental and caregiver feeding practices and growth, size, and body composition outcomes: A Systematic Review
}

The Pregnancy and Birth to 24 Months Project

Published date: April 15, 2019

Nutrition Evidence Systematic Review

Center for Nutrition Policy and Promotion

Food and Nutrition Service

U.S. Department of Agriculture

3101 Park Center Drive

Alexandria, Virginia 
This systematic review was conducted for the Pregnancy and Birth to 24 Months Project (P/B-24) by the Nutrition Evidence Systematic Review (NESR) team at the Center for Nutrition Policy and Promotion, Food and Nutrition Service, USDA. All systematic reviews from the P/B-24 Project are available on the NESR website: https://nesr.usda.gov.

Conclusion statements drawn as part of this systematic review describe the state of science related to the specific question examined. Conclusion statements do not draw implications, and should not be interpreted as dietary guidance.

The contents of this document may be used and reprinted without permission. Endorsements by NESR, the Center for Nutrition Policy and Promotion, the Food and Nutrition Service, or the U.S. Department of Agriculture (USDA) of derivative products developed from this work may not be stated or implied.

In accordance with Federal civil rights law and USDA civil rights regulations and policies, the USDA, its Agencies, offices, and employees, and institutions participating in or administering USDA programs are prohibited from discriminating based on race, color, national origin, religion, sex, gender identity (including gender expression), sexual orientation, disability, age, marital status, family/parental status, income derived from a public assistance program, political beliefs, or reprisal or retaliation for prior civil rights activity, in any program or activity conducted or funded by USDA (not all bases apply to all programs). Remedies and complaint filing deadlines vary by program or incident.

Persons with disabilities who require alternative means of communication for program information (e.g., Braille, large print, audiotape, American Sign Language, etc.) should contact the responsible Agency or USDA's TARGET Center at (202) 720-2600 (voice and TTY) or contact USDA through the Federal Relay Service at (800) 877-8339. Additionally, program information may be made available in languages other than English.

To file a program discrimination complaint, complete the USDA Program Discrimination Complaint Form, AD3027, found online at How to File a Program Discrimination Complaint and at any USDA office or write a letter addressed to USDA and provide in the letter all of the information requested in the form. To request a copy of the complaint form, call (866) 632-9992. Submit your completed form or letter to USDA by: (1) mail: U.S. Department of Agriculture, Office of the Assistant Secretary for Civil Rights, 1400 Independence Avenue, SW, Washington, D.C. 20250-9410; (2) fax: (202) 690-7442; or (3) email: program.intake@usda.gov.

USDA is an equal opportunity provider, employer, and lender.

\section{Suggested citation for this systematic review:}

Nutrition Evidence Systematic Review Team and Flavor Exposure and Feeding Practices Technical Expert Collaborative. Parental and caregiver feeding practices and growth, size, and body composition outcomes: A Systematic Review. Pregnancy and Birth to 24 Months Project. Alexandria, VA: U.S. Department of Agriculture, Food and Nutrition Service, Center for Nutrition Policy and Promotion, February 2019. Available at: https://nesr.usda.gov/project-specific-overview-pb-24-0.

This systematic review has also been published in the American Journal of Clinical Nutrition: Spill MK, Callahan EH, Shapiro MJ, Spahn JM, Wong YP, Benjamin-Neelon SE, et al. Caregiver feeding practices and child weight outcomes: a systematic review. Am J Clin Nutr. 2019;109(7):990S-1002S. doi: 10.1093/ajen/nqy276.

Related citations are published in the American Journal of Clinical Nutrition: TBD, in NLM format

- P/B-24 Project overview: Stoody EE, Spahn JM, Casavale KO. The Pregnancy and Birth to 24 Months Project: a series of systematic reviews on diet and health. Am J Clin Nutr. 2019;109(7):685S-97S. doi: 10.1093/ajcn/nqy372.

- P/B-24 systematic review methodology: Obbagy JE, Spahn JM, Wong YP, Psota TL, Spill MK, Dreibelbis C, et al. Systematic review methodology used in the Pregnancy and Birth to 24 Months 
- Related systematic reviews from the P/B-24 Project:

o Spill MK, Johns K, Callahan EH, Shapiro MJ, Wong YP, Benjamin-Neelon SE, et al. Repeated exposure to food and food acceptability in infants and toddlers: a systematic review. Am J Clin Nutr. 2019;109(7):978S-89S. doi: 10.1093/ajcn/nqy308.

- Spahn JM, Callahan EH, Spill MK, Wong YP, Benjamin-Neelon SE, Birch L, et al. Influence of maternal diet on flavor transfer to amniotic fluid and breast milk and children's responses: a systematic review. Am J Clin Nutr. 2019;109(7):1003S-26S. doi: 10.1093/ajcn/nqy240.

\section{ACKNOWLEDGEMENTS}

Flavor exposure \& Feeding practices Technical Expert Collaborative (TEC):

- Sara Benjamin-Neelon, PhD, MPH, RD, Johns Hopkins University

- Leann Birch, PhD, University of Georgia

- Maureen Black, PhD, University of Maryland School of Medicine and RTI International

- Ronette Briefel, DrPH, MPH, RD, Mathematica Policy Institute

- John Cook, PhD, MAEd, Boston Medical Center

- Myles Faith, PhD, University at Buffalo

- Julie Mennella, PhD, Monell Chemical Senses Center

\section{Nutrition Evidence Systematic Review (NESR) Team:}

- Maureen Spilli, PhD, Panum Group, Lead analyst

- Emily Goweri, MS, Panum Group, Analyst (from 11/2016)

- Kirsten Johnsi, MS, Panum Group, Analyst (until 01/2017)

- Myra Shapiro', PhD, Panum Group, Analyst (from 01/2017)

- Joanne Spahn, MS, USDA, Analyst

- Yat Ping Wong, MLS, MPH, USDA, Librarian

\section{Project Leads:}

- Kellie Casavale, PhD, RD, HHS

- Joanne Spahn, MS, RD, FADA, USDA

- Eve Essery Stoody, PhD, USDA

Federal Expert Group (FEG)-Technical Expert Collaborative (TEC) Liaisons:

- Andrea Farmer, MS, RD, LD, USDA (until 05/2016)

- Heather Hamner, PhD, MS, MPH, CDC (from 05/2016)

- Cria Perrine, PhD, CDC (from 10/2016)

All TEC and NESR team members, Project leads, and FEG-TEC liaisons participated in establishing the research questions, analytic framework, and study inclusion and exclusion criteria. MKS, KJ, EHC, MJS, and JMS wrote the manuscript, screened, extracted data and assessed risk of bias independently. YPW designed and conducted the literature search. SBN, LB, MB, RB, JTC, MSF, and JAM designed the protocol and provided substantive input to evidence synthesis, conclusion statement. KOC,

i Under contract with the Food and Nutrition Service, United States Department of Agriculture. 
JMS, and EES provided oversight of the project. All authors critically reviewed the manuscript and approved the final version. The authors declare no conflicts of interest.

FUNDING SOURCE: United States Department of Agriculture, Food and Nutrition Service, Center for Nutrition Policy and Promotion, Alexandria, VA 


\section{TABLE OF CONTENTS}

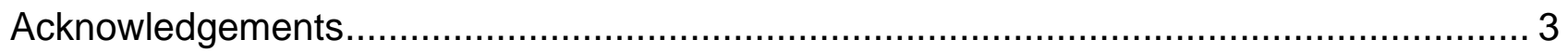

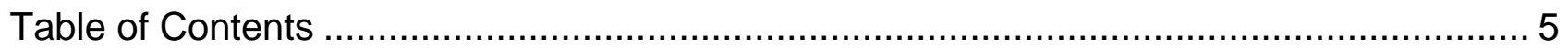

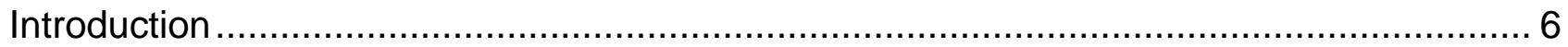

What is the relationship between parental and caregiver feeding practices and growth,

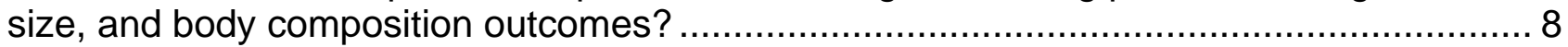

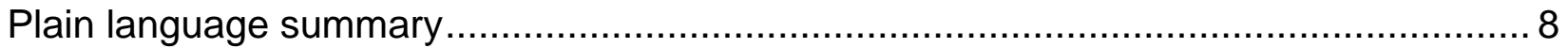

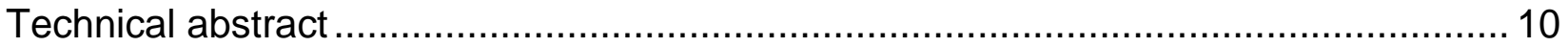

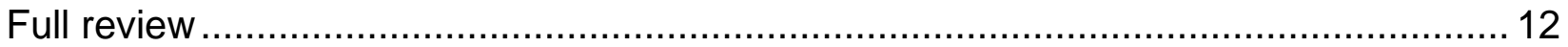

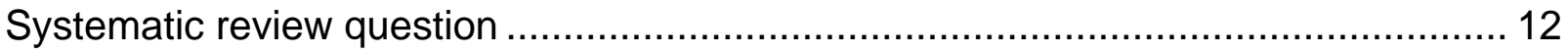

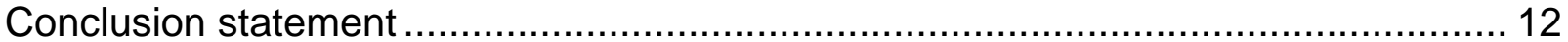

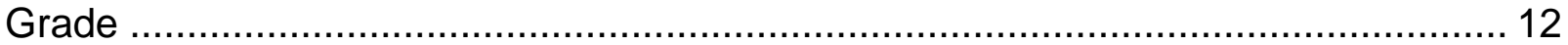

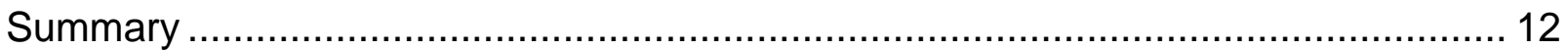

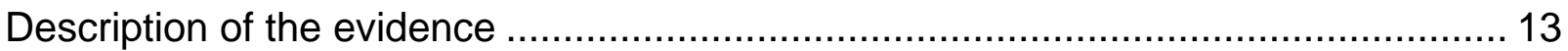

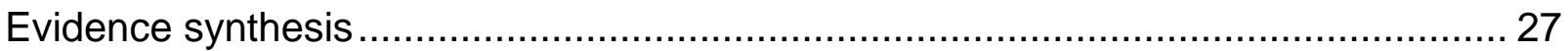

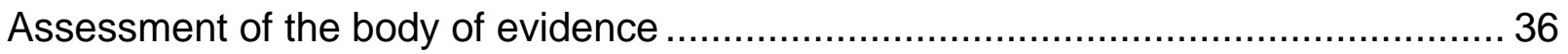

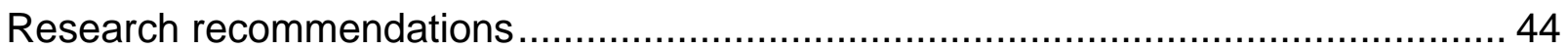

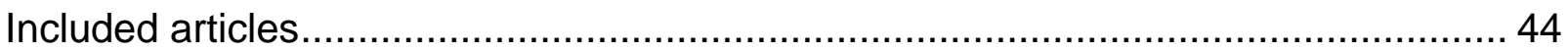

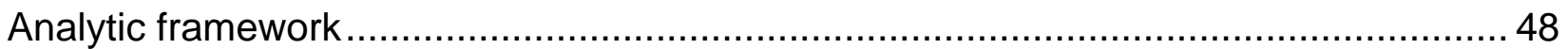

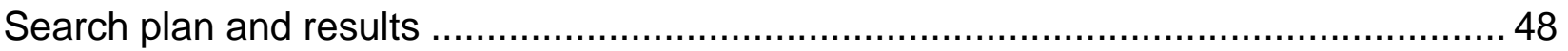

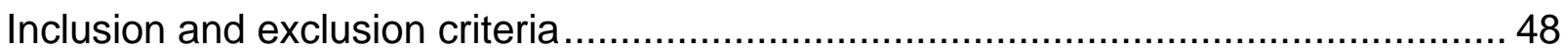

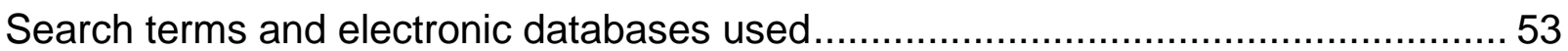

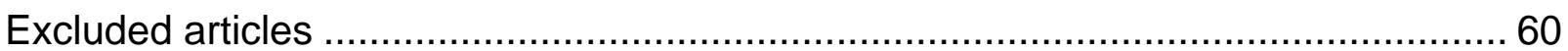

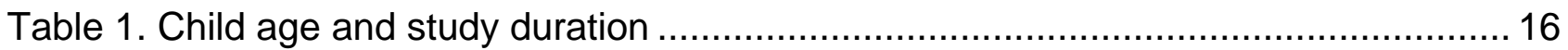

Table 2. Overview of associations between feeding practices and child weight outcomes 38

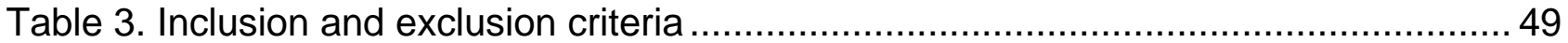

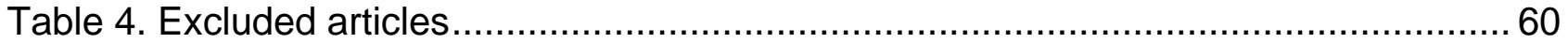

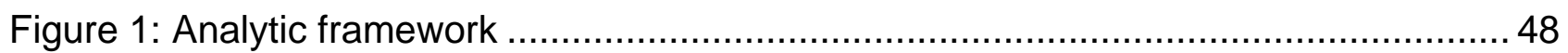

Figure 2: Flow chart of literature search and screening results................................... 58 
This document describes a systematic review conducted to answer the following question: what is the relationship between parental and caregiver feeding practices and growth, size, and body composition outcomes? This systematic review was conducted as part of the Pregnancy and Birth to 24 Months (P/B-24) Project by USDA's Nutrition Evidence Systematic Review (NESR).

The purpose of the P/B-24 Project was to conduct a series of systematic reviews on diet and health for women who are pregnant and for infants and toddlers from birth to 24 months of age. This project was a joint initiative led by USDA and HHS, and USDA's NESR carried out all of the systematic reviews. A Federal Expert Group (FEG), a broadly representative group of Federal researchers and program leaders, also provided input throughout the P/B-24 Project. More information about the P/B-24 Project has been published $\mathrm{d}^{\mathrm{ii}}$ and is available on the NESR website: https://nesr.usda.gov/project-specificoverview-pb-24-0.

NESR, formerly known as the Nutrition Evidence Library (NEL), specializes in conducting food- and nutrition-related systematic reviews using a rigorous, protocol-driven methodology. To conduct each P/B-24 systematic review, NESR's staff worked with a Technical Expert Collaborative (TEC), which is a group of 7-8 leading subject matter experts.

NESR's systematic review methodology involves developing and prioritizing systematic review questions, searching for and selecting studies, extracting and assessing the risk of bias of data from each included study, synthesizing the evidence, developing a conclusion statement, grading the evidence underlying the conclusion statement, and recommending future research. A detailed description of the methodology used in conducting systematic reviews for the P/B-24 Project has been publishediii and is available on the NESR website: https://nesr.usda.gov/pb-24-project-methodology-0. In addition, starting on page 48, this document includes details about the methodology as it was applied to the systematic review described herein. An analytic framework that illustrates the overall scope of the question, including the population, the interventions and/or exposures, comparators, and outcomes of interest, is found on page 48. In addition, the literature search plan, that was used to identify studies included in this systematic review is found on page 48.

\footnotetext{
ii Stoody EE, Spahn JM, Casavale KO. The Pregnancy and Birth to 24 Months Project: a series of systematic reviews on diet and health. Am J Clin Nutr. 2019;109(7):685S-97S. doi: 10.1093/ajen/nqy372.

iii Obbagy JE, Spahn JM, Wong YP, Psota TL, Spill MK, Dreibelbis C, et al. Systematic review methodology used in the Pregnancy and Birth to 24 Months Project. Am J Clin Nutr. 2019;109(7):698S704S. doi: 10.1093/ajcn/nqy226.
} 


\section{List of abbreviations}

$\begin{array}{ll}\text { Abbreviation } & \text { Full name } \\ \text { BMI } & \text { Body mass index } \\ \text { BMIZ } & \text { Body mass index z-score } \\ \text { HHS } & \text { United States Department of Health and Human Services } \\ \text { NEL } & \text { Nutrition Evidence Library } \\ \text { NEL BAT } & \text { NEL Bias Assessment Tool } \\ \text { RCT } & \text { Randomized controlled trial } \\ \text { RoB } & \text { Risk of bias } \\ \text { SR } & \text { Systematic Review } \\ \text { TEC } & \text { Technical Expert Collaborative } \\ \text { USDA } & \text { United States Department of Agriculture } \\ \text { WAZ } & \text { Weight-for-age z-score } \\ \text { WLZ } & \text { Weight-for-length z-score }\end{array}$




\section{WHAT IS THE RELATIONSHIP BETWEEN PARENTAL AND CAREGIVER FEEDING PRACTICES AND GROWTH, SIZE, AND BODY COMPOSITION OUTCOMES?}

\section{PLAIN LANGUAGE SUMMARY}

What is the question?

- The question is: What is the relationship between caregiver feeding practices for children from birth to 24 months old and the weight, growth, and body composition outcomes?

What is the answer to the question?

- Moderate evidence from randomized controlled trials suggests that providing responsive feeding guidance to mothers to recognize and respond appropriately to a child's hunger and satiety cues can contribute to "normal" weight gain and/or "normal" weight status in children two years and younger compared to children whose mothers did not receive responsive feeding guidance.

- Moderate evidence from longitudinal cohort studies indicates an association between maternal feeding practices and the child's weight status and/or weight gain, but the direction of effect has not been adequately studied. Restrictive feeding practices are associated with increased weight gain and higher weight status and pressuring feeding practices are associated with decreased weight gain and lower weight status. Evidence suggests mothers' feeding practices are related to concerns about children's body weight.

Why was this question asked?

- This important public health question was identified and prioritized as part of the U.S. Department of Agriculture and Department of Health and Human Services Pregnancy and Birth to 24 Months Project.

\section{How was this question answered?}

- A team of Nutrition Evidence Systematic Review staff conducted a systematic review in collaboration with a group of experts called a Technical Expert Collaborative

\section{What is the population of interest?}

- Caregiver feeding practices were studied when generally healthy infants and toddlers were between the ages of 0 to 24 months; growth, size, and body composition outcomes were examined in the children through 18 years of age.

\section{What evidence was found?}

- 27 publications were included: 6 RCTs, 2 non-randomized controlled trials, 19 longitudinal cohort studies

o Feeding practices were examined when children were newborns to 22 months of age; outcomes were collected in children up to 6 years of age.

- 4 controlled trials demonstrated that interventions that taught parents about responsive feeding led to lower weight outcomes in children two years and younger compared to children in a control group. 
- The longitudinal cohort studies examined a variety of feeding practices, including: pressuring, restriction, responsive, feeding in the absence of hunger, indulgent, concern about weight/intake, baby led vs. standard weaning, control, monitoring, modelling, laissez-faire, and authoritative.

- While there were some inconsistencies, there is evidence that restrictive feeding practices are positively associated with higher child weight outcomes and pressuring-to-eat practices are associated with lower child weight outcomes.

- The relationship between caregiver feeding practices and child's weight is not unidirectional. Evidence indicates that parental concern of child's weight is related to the child's weight status and influences their feeding practices.

- There are limitations in the evidence, including inconsistent methodology, including the interventions, exposures, outcomes, child age, and time to followup, and lack of information on caregiver motivations in decision-making related to infant feeding.

\section{How up-to-date is this review?}

- This review includes literature from 01/1980 to 01/2017. 


\section{TECHNICAL ABSTRACT}

\section{Background}

- The relationship between caregiver feeding practices and child weight outcomes is likely bi-directional and influenced by the child's actual or perceived weight and behaviors during feeding, as well as maternal variables; this review focuses on studies that measured caregiver feeding practices as the independent variable and children weight as the outcome.

- Feeding practices are the strategies or behaviors parents use to direct child eating.

- Responsive feeding is characterized by caregiver guidance and recognition of the child's cues of hunger and satiety.

- Non-responsive feeding is dominated by a lack of reciprocity between the parent and child, with the caregiver taking excessive control of the feeding situation (pressuring or restricting food intake), the child controlling the feeding situation (indulgent feeding), or the caregiver being uninvolved during meals (uninvolved feeding/ laissez-faire), using feeding as a default first response to infant distress (feeding to soothe).

- Systematic reviews were conducted as part of the U.S. Department of Agriculture and Department of Health and Human Services Pregnancy and Birth to 24 Months Project.

- The goal of this systematic review was to examine the following question: What is the relationship between caregiver feeding practices for children from birth to 24 months old and the weight, growth, and body composition of their children?

\section{Conclusion Statement and Grades}

- Moderate evidence from randomized controlled trials suggests that providing responsive feeding guidance to mothers to recognize and respond appropriately to a child's hunger and satiety cues can contribute to "normal" weight gain and/or "normal" weight status in children two years and younger compared to children whose mothers did not receive responsive feeding guidance. Grade: Moderate

- Moderate evidence from longitudinal cohort studies indicates an association between maternal feeding practices and the child's weight status and/or weight gain, but the direction of effect has not been adequately studied. Restrictive feeding practices are associated with increased weight gain and higher weight status and pressuring feeding practices are associated with decreased weight gain and lower weight status. Evidence suggests mothers' feeding practices are related to concerns about children's body weight. Grade: Moderate

\section{Methods}

- This systematic review was conducted by a team of staff from the Nutrition Evidence Systematic Review team in collaboration with a Technical Expert Collaborative.

- Literature search was conducted using 4 databases (PubMed, Cochrane, Embase, and CINAHL) to identify articles that evaluated the intervention or exposure of caregiver feeding practices and the outcomes of growth, size, and body composition. A manual search was conducted to identify articles that may not have been included in the electronic databases searched. Articles were 
screened by two authors independently for inclusion based on pre-determined criteria.

- Data extraction and risk of bias assessment were conducted for each included study, and both were checked for accuracy. The body of evidence was qualitatively synthesized to inform development of a conclusion statement(s), and the strength of evidence was graded using pre-established criteria evaluating the body of evidence on internal validity/risk of bias, adequacy, consistency, impact, and generalizability.

\section{Summary of Evidence}

- Twenty-seven articles (6 RCT, 2 non-randomized controlled trials, 19 longitudinal cohort studies) met criteria for inclusion that examined caregiver feeding practices and child growth, size, and body composition outcomes

- Studies took place in the U.S., Australia, the U.K., the Netherlands, and China.

- Feeding practices were examined when children were newborns to 22 months of age; outcomes were collected in children up to 6 years of age.

- Caregivers were predominantly mothers (99\%), many of whom were educated to at least the high school level.

- 4 controlled trials demonstrated that interventions that taught parents about responsive feeding led to lower weight outcomes in children two years and younger compared to children in a control group.

- The longitudinal cohort studies examined a variety of feeding practices, including: pressuring $(n=8)$, restriction $(n=7)$, responsive $(n=6)$, feeding in the absence of hunger $(n=3)$, indulgent $(n=2)$, concern about weight/intake $(n=2)$, baby led vs. standard weaning $(n=1)$, control $(n=1)$, monitoring $(n=1)$, modelling $(n=1)$, laissez-faire $(n=1)$, and authoritative $(n=1)$.

- While there were some inconsistencies, there is evidence that restrictive feeding practices are positively associated with higher child weight outcomes (WAZ, WLZ, BMIZ, and risk of overweight ) and pressuring-to-eat practices are associated with lower child weight outcomes (WAZ, excess weight (WAZ >1; WAZ >90th percentile), WLZ, standardized weight, and weight gain).

- The relationship between caregiver feeding practices and child's weight is not unidirectional. Evidence indicates that parental concern of child's weight is related to the child's weight status and influences their feeding practices.

- There are limitations in the evidence, including inconsistent methodology, including the interventions, exposures, outcomes, child age, and time to followup, and lack of information on caregiver motivations in decision-making related to infant feeding .

- There are limitations in the evidence, including:

o Inconsistencies in methodology, including the interventions, exposures, outcomes, child age, and time to follow-up

o Lack of information on caregiver motivations for making decisions about infant feeding

o Lack of information on the stability of feeding practices over time or throughout different developmental periods, particularly during the transition from breast or bottle-feeding to feeding complementary foods and beverages 


\section{FULL REVIEW}

\section{Systematic review question}

What is the relationship between caregiver feeding practices for children from birth to 24 months old and the weight, growth, and body composition outcomes?

\section{Conclusion statement}

Moderate evidence from randomized controlled trials suggests that providing responsive feeding guidance to mothers to recognize and respond appropriately to a child's hunger and satiety cues can contribute to "normal" weight gain and/or "normal" weight status in children two years and younger compared to children whose mothers did not receive responsive feeding guidance.

Moderate evidence from longitudinal cohort studies indicates an association between maternal feeding practices and the child's weight status and/or weight gain, but the direction of effect has not been adequately studied. Restrictive feeding practices are associated with increased weight gain and higher weight status and pressuring feeding practices are associated with decreased weight gain and lower weight status.

Evidence suggests mothers' feeding practices are related to concerns about children's body weight.

\section{Grade}

\section{Moderate}

\section{Summary}

- This body of evidence includes 27 publications, eight from controlled trials and 19 from longitudinal cohort studies, published from 1982 to 2016, that took place in the US, Australia, the UK, the Netherlands, and China.

- Caregivers were predominantly mothers (99\%), with few fathers, and in one study from China, grandparents. Six studies were with a primarily non-white population, but for the full body of evidence most of the participants were white, educated women.

- This body of evidence includes studies that examined feeding practices when children were newborns to 22 months of age and outcomes were collected in children up to 6 years of age. The body of evidence includes studies that measured feeding practices during different phases of infant/toddler feeding including feeding of breastmilk and/or formula, complementary foods, and table foods.

- Caregiver feeding practices are influenced by many factors including caregivers' perception of and actual differences in children's health status, weight status, and temperament; therefore, there is a bi-directional relationship between feeding practices and infant characteristics that should be considered when 
interpreting findings.

- Normal weight gain is important in childhood development; therefore, caution should be used when interpreting associations between feeding practices and higher or lower weight outcomes. It is important to note that "normal" weight gain and weight status are measured and defined differently across the studies (see description of evidence, outcome measures).

- Of the six controlled trials in the body of evidence, four strong trials demonstrated that interventions that taught parents about responsive feeding (recognizing and responding to infant's hunger and satiety cues) led to lower weight outcomes (lower BMI z-scores, lower weight-for-length z-scores, less likely to be overweight, less rapid weight gain, and lower conditional weight gain) in children two years and younger compared to children in a control group. (The remaining two trials had significant limitations and were therefore were not considered as strongly in development of the conclusion statement.)

- One controlled trial within the body of evidence had follow-up times of 9months, 20-months, and 4.5 years after the intervention. Children of mothers who were taught responsive feeding practices had lower BMI z-scores and less rapid weight gain at a 9-month follow-up but not at the 20 month or 4.5 year follow-up compared to children in the control group; however, there was a difference in parental feeding practices between the groups at each follow-up time point.

- The longitudinal cohort studies examined a variety of feeding practices beyond responsive feeding. While there were some inconsistencies, there is evidence that restrictive feeding practices are positively associated with higher child weight outcomes (WAZ, WLZ, BMIZ, and risk of overweight) and pressuring-toeat is associated with lower child weight outcomes (WAZ, excess weight (WAZ $>1$; WAZ $>90^{\text {th }}$ percentile), WLZ, standardized weight, and weight gain).

- There were several limitations in this body of evidence. Within the intervention studies, limitations include generalizability, variation in methods including the use of different outcome measures and follow-up times. Within the cohort studies, limitations include generalizability, parental report of feeding practices and outcome data, feeding practices data collected once without follow-up and heterogeneous methods including different outcome measures, child ages, and length of time to follow-up. Research is needed in more diverse populations with consistent methodological approaches and objective measures to better address the systematic review question.

\section{Description of the evidence}

This systematic review included articles that address the relationship between parental and caregiver feeding practices and child growth, size, and body composition. The search included articles from countries categorized as high or very high on the Human Development Index (2014) and published from 1980 to January 2017. Studies included 
generally healthy populations of caregivers and infants and toddlers that were from birth to 24 months old at the time of the exposure/intervention. Studies were not included if they specifically enrolled infants with gestational age $<37$ weeks or infants who were small for gestational age $(<2500 \mathrm{~g})$. The independent variable was parental and caregiver feeding practices, and was defined as the strategies or behaviors of the parent or caregiver used to direct child eating. Examples of feeding practices include pressuring to eat, restriction, and responsiveness to satiety and hunger cues. The dependent variable, infant growth, size, and/or body composition, specifically included: weight-for-age, length/height-for-age, BMI, BMI percentiles-for-age/sex, and z-score, waist circumference, skin-folds, weight change, weight status change, $\%$ fat mass, $\%$ fat free mass, incidence and prevalence of healthy weight, overweight, and obesity, and incidence and prevalence of underweight, failure to thrive, stunting, or wasting.

\section{Twenty seven publications were included in the body of evidence.}

\section{Study design}

- Controlled trials: (8 publications)

o Four Randomized Controlled Trials (6 publications): Daniels, 2012; Daniels, 2013; Daniels, 2015; Kavanagh, 2008; Paul, 2011; Savage 2016

o Two Non-randomized Controlled Trials: De Carvalho, 1983; Machuca, 2016

- Observational studies: 17 cohorts (19 publications total)

o The 17 cohorts included:

- The Child and Family Health Study (Gregory, 2011)

- Dutch KOALA Birth Cohort (Gubbels, 2011)

- Colorado Adoption Project (Hittner, 2016)

- Infant Feeding Practices Study II (Li, 2008)

- Study of Early Child Care and Youth Development (Lumeng, 2012)

- Millennium Infant Study (Wright, 2006)

- Project Viva cohort (Taveras, 2006; Rifas-Shiman, 2011)

- Unnamed cohort (Farrow, 2006; Farrow, 2008)

- Remaining 10 publications were from convenient samples (Brown, 2015; Chaidez, 2014; Dinkevich, 2015; Ma, 2015; Morris, 1982; Saxon, 2002; Stifter, 2015; Thompson, 2013; Worobey, 2009)

o All papers were from prospective cohort studies, with the exception of one retrospective cohort study (Saxon, 2002)

\section{Country}

- United States: 17 papers

o Controlled trials: De Carvalho, 1983; Kavanagh, 2008; Machuca, 2016; Paul, 2011; Savage 2016

o Cohort studies: Chaidez, 2014; Dinkevich, 2015; Hittner, 2016; Li, 2008; Lumeng 2012; Morris, 1982; Rifas-Shiman, 2011; Saxon, 2002; Stifter, 2015; Taveras, 2006; Thompson, 2013; Worobey, 2009

- Australia: Four papers

o Controlled trials: Daniels, 2012; Daniels, 2013; Daniels, 2015; 
o Cohort study: Gregory, 2011

- United Kingdom: Four papers

o Cohort studies: Brown, 2015; Farrow, 2006; Farrow, 2008; Wright, 2006

- The Netherlands: One paper

o Cohort study: Gubbels, 2011

- China: One paper

o Cohort study: Ma, 2015

\section{Sample size}

- In the controlled trials, sample sizes ranged from an analytic $\mathrm{n}$ of 28 (De Carvalho, 1983) to 598 (Daniels, 2012). In the cohort studies, sample sizes ranged from an analytic $n$ of 48 (Saxon, 2002) to 2557 (Gubbels, 2011).

o Ten papers had $<100$ participants:

- Controlled trial: De Carvalho, 1983, Kavanagh, 2008;

- Cohort studies: Chaidez, 2014; Dinkevich, 2015; Farrow, 2006; Farrow, 2008; Gregory, 2011; Hittner, 2016; Saxon, 2002; Worobey, 2009

o Nine papers had between 100 and 500 participants:

- Controlled trials: Daniels, 2015; Machuca, 2016; Paul, 2011; Savage 2016;

- Cohort studies: Brown, 2015; Ma, 2015; Morris, 1982; Stifter, 2015; Thompson, 2013

o Four papers had between 500 and 1,000 participants:

- Controlled trials: Daniels, 2012; Daniels, 2013;

- Cohort studies: Rifas-Shiman, 2011; Wright, 2006

o Four papers had $>1,000$ participants:

- Cohort studies: Gubbels, 2011; Li, 2008; Lumeng, 2012; Taveras, 2006

\section{Caregiver}

- In 26 of the 27 papers, the caregivers were mostly or all mothers (>99\% mothers). However, grandparents were also prominent caregivers in one study (Ma, 2015).

\section{Demographics}

- Within the full body of evidence most of the caregiver participants were women who were white (Daniels [2012, 2013, 2015]; Paul, 2011; Savage, 2016; Saxon, 2002; Taveras, 2006; Li, 2008; Gregory, 2011; Rifas-Shiman, 2011; Lumeng, 2012; Brown, 2015; Dinkevich, 2015; Ma, 2015; Stifter, 2015) and educated to at least the high school level (Paul, 2011; Savage, 2016; Morris, 1982; Saxon, 2002; Taveras, 2006; Wright, 2006; Li, 2008; Rifas-Shiman, 2011; Lumeng, 2012; Stifter, 2015; Hittner, 2016).

- Seven studies were conducted in diverse populations and/or lower socioeconomic populations:

o Chaidez, 2014:

- Ethnicity: 100\% Latino; Maternal birthplace: US: 16\%; Mexico/other: 84\%; Maternal language: Spanish: 81\%, 
English/bilingual: $13 \%$

- Mothers were recruited from WIC program (100\% were participants); monthly household income, median (range): \$1366 $(\$ 300-\$ 6549)$

o Dinkevich, 2015:

- $100 \%$ African-American

- $58 \%$ income $<\$ 30 \mathrm{~K} ; 79 \%$ receiving Medicaid

o Ma, 2015:

- China-based study population

o Machuca, 2016:

- Ethnicity, Hispanic: 64\%; Race: Multiracial: 38\%, Black/AfricanAmerican: 37\%, White: 17\%, Other: 1\%, Declined: 6\%

- $100 \%$ of participants residents of the South Bronx

o Thompson, 2013:

- $100 \%$ African-American

o Worobey, 2009:

- Race/Ethnicity: 24\% Black, 76\% Hispanic; Country of origin: $27 \%$ USA, 54\% Mexico, 12\% Dominican Republic, 7\% Puerto Rico, Columbia, Honduras, and Peru

- Mothers were recruited from WIC program (100\% were participants); the mean highest year of schooling was 9.35 $(\mathrm{SD}=3.28)$

o Wright, 2006:

- Cohort from the UK, 99.2\% of which were White British-origin: $71 \%$ mothers educated to 16 years old; $24 \%$ lived in unwaged households

\section{Timing of study (age of children and study duration)}

- Mean age at initial intervention/exposure measurement: At the initial intervention/exposure measurement, mean age of infants ranged from birth (Controlled trial: De Carvalho, 1983; Cohort study: Saxon, 2002) to 22 months in the cohort studies (Chaidez, 2014); see table 1

- Mean age at final outcome assessment: At the time of the final outcome assessment, mean age of infants ranged from 35 days (De Carvalho, 1983) to 5 years (Daniels, 2015) in the controlled trials and from 6 months (Saxon, 2002) to 6 years (Hittner, 2016) in the cohort studies see table 1

- Length of time from initial exposure to final outcome assessment:

Controlled trials ranged from 35 days (De Carvalho, 1983) to 4.5 years (Daniels, 2015). Cohort studies ranged from 6 months (Chaidez, 2014; Morris, 1982;

Saxon, 2002) to 5 years (Hittner, 2016) see table 1

Table 1. Child age and study duration

\begin{tabular}{ccccc}
\hline Article & $\begin{array}{c}\text { Child age at intervention } \\
\text { start/ initial exposure } \\
\text { measurement (mean) }\end{array}$ & $\begin{array}{c}\text { Child age at final } \\
\text { assessment (mean) }\end{array}$ & $\begin{array}{c}\text { Duration (from initial } \\
\text { exposure to final } \\
\text { outcome) }\end{array}$ \\
\hline$\overline{0}$ & Daniels, 2012 & $\sim 4 \mathrm{mo}$ & $\sim 13 \mathrm{mo}$ & $9 \mathrm{mo}$ \\
\hline
\end{tabular}




\begin{tabular}{|c|c|c|c|c|}
\hline \multicolumn{2}{|c|}{ Daniels, 2015} & $\sim 4 \mathrm{mo}$ & $5 y$ & $-4.5 y$ \\
\hline & Machuca, 2016 & $\sim 1 \mathrm{mo}$ & $24 \mathrm{mo}$ & $23 \mathrm{mo}$ \\
\hline & Paul, 2011 & $-3 w k$ & $12 \mathrm{mo}$ & $\sim 11 \mathrm{mo}$ \\
\hline & Savage 2016 & $\sim 4$ wks & $12 \mathrm{mo}$ & $\sim 11 \mathrm{mo}$ \\
\hline & De Carvalho, 1983 & Birth & $35 d$ & $35 d$ \\
\hline & Kavanagh, 2008 & $-6 w k$ & $\sim 4 \mathrm{mo}$ & $-3 \mathrm{mo}$ \\
\hline & Brown, 2015 & $\sim 9 \mathrm{mo}$ & $\sim 21 \mathrm{mo}$ & $\sim 12 \mathrm{mo}$ \\
\hline & Chaidez, 2014 & $\sim 22 \mathrm{mo}$ & $\sim 28 \mathrm{mo}$ & $\sim 6 \mathrm{mo}$ \\
\hline & Dinkevich, 2015 & $\sim 9 \mathrm{mo}$ & $30 \mathrm{mo}$ & $\sim 21 \mathrm{mo}$ \\
\hline & Farrow, 2006 & $6 \mathrm{mo}$ & $12 \mathrm{mo}$ & $6 \mathrm{mo}$ \\
\hline & Farrow, 2008 & $12 \mathrm{mo}$ & $24 \mathrm{mo}$ & $12 \mathrm{mo}$ \\
\hline & Gregory, 2011 & $12 \mathrm{mo}$ & $24 \mathrm{mo}$ & $12 \mathrm{mo}$ \\
\hline & Gubbels, 2011 & $3 \mathrm{mo}$ & $4 y$ & $4 y$ \\
\hline$\underline{g}$ & Hittner, 2016 & $12 \mathrm{mo}$ & $6 y$ & $5 y$ \\
\hline 일 & Li, 2008 & $1 \mathrm{mo}$ & $12 \mathrm{mo}$ & $12 \mathrm{mo}$ \\
\hline$t_{0}^{\infty}$ & Lumeng 2012 & $15 \mathrm{mo}$ & $3 y$ & $21 \mathrm{mo}$ \\
\hline$\frac{1}{0}$ & Ma, 2015 & $6 \mathrm{mo}$ & $18 \mathrm{mo}$ & $12 \mathrm{mo}$ \\
\hline $\bar{u}$ & Morris, 1982 & $3 \mathrm{mo}$ & $9 \mathrm{mo}$ & $6 \mathrm{mo}$ \\
\hline & Rifas-Shiman, 2011 & $12 \mathrm{mo}$ & $3 y$ & $24 \mathrm{mo}$ \\
\hline & Saxon, 2002 & Birth & $6 \mathrm{mo}$ & $6 \mathrm{mo}$ \\
\hline & Stifter, 2015 & $6 \mathrm{mo}$ & $18 \mathrm{mo}$ & $12 \mathrm{mo}$ \\
\hline & Taveras, 2006 & $12 \mathrm{mo}$ & $3 y$ & $24 \mathrm{mo}$ \\
\hline & Thompson, 2013 & $3 \mathrm{mo}$ & $18 \mathrm{mo}$ & $15 \mathrm{mo}$ \\
\hline & Worobey, 2009 & $3 \mathrm{mo}$ & $12 \mathrm{mo}$ & $9 \mathrm{mo}$ \\
\hline & Wright, 2006 & $6 w k$ & $13 \mathrm{mo}$ & $13 \mathrm{mo}$ \\
\hline
\end{tabular}

\section{Intervention/Exposures}

- Controlled trials: each intervention had some component related to responsive feeding, i.e. responding to infant satiety and hunger cues

o In the NOURISH trial (Daniels, 2012; Daniels, 2013; Daniels, 2015) mother-infant dyads were randomly allocated to:

- Control $(n=293)$ : self-directed access to usual community child health services;

- Intervention ( $\mathrm{n}=273)$ : comprehensive skills-based program with cognitive behavioral approach focused on feeding and parenting practices; starting when children were 4-6 mo old; 2 modules each having 6 fortnightly group sessions (10-15 mothers/group; 11.5h/session), over 3 months:

- Theme 1: increased exposure to healthy foods and 
decreased exposure to unhealthy foods to promote development of healthy food preferences (module 1 )

- Theme 2: responsive feeding that recognizes and responds appropriately to infant cues of hunger and satiety to promote self-regulation of intake (module 2)

- Theme 3: positive parenting (warmth, encouragement of autonomy, and self-efficacy (modules 1 and 2)

o In the De Carvalho, 1983 non-randomized controlled trial with the purpose of investigating the effects of frequent and unrestricted feeding on infants milk intake (and milk production), mothers-infant dyads were allocated to one of two groups based on the month of delivery (control group: July and August; intervention group: September and October). All infants were exclusively breastfed.

- Control, "scheduled feeding" group $(n=16)$ : mothers told to breast feed on schedule, every 3 to 4 hours,

- Intervention, "on demand" group ( $n=12)$ : mothers told to breast fed on demand, whenever the infant seemed to be hungry (fussiness, sucking of fingers, mouthing movements), and encouraged to feed frequently

o The Kavanagh, 2008 study provided a nutrition education intervention within the Special Supplemental Nutrition Program for Women, Infants, and Children (WIC). Both intervention and control arms consisted of one 45-60 minute class which directly replaced an existing WIC class.

- Control $(n=20)$ : general guidance on infant feeding with additional information on low-cost ways of providing nutritionally balanced meals to infants once they began eating solid foods;

- Intervention $(n=18)$ : general guidance on infant feeding and additional key messages:

- Be aware of and responsive to the infant's satiety cues: early cues include slower sucking, getting sleepy, beginning to lose interest in the feed; later cues include turning away, dribbling milk, biting the nipple, falling asleep, spitting up; Encouraged to stop feeding when infant demonstrated early satiety cues;

- Prepare no more formula than $6 \mathrm{oz}$ at a feed (and to prepare additional only if infant was still hungry)

o In the non-randomized controlled trial by Machuca, 2016, mother-infant dyads were enrolled before infants were 2 months old. Mothers chose if they wanted to participate in the intervention. The control group was a subsample of mothers who chose not to participate in the intervention.

- Control group ( $n=140)$ : standard care

- Well Baby Group (WBG) intervention ( $n=47)$ : same one-on-one traditional care as control plus 3 additional group sessions; groups sessions lasted 2 hours, with 30 minutes on nutrition including recognizing hunger and satiety cues, understanding how to avoid overfeeding, and using soothing techniques rather than food 
o In the SLIMTIME intervention (Paul, 2011) mother-infant dyads were randomized into 4 groups (2 interventions; 2x2 design):

- Soothe/sleep only $(n=29)$ : delivered by research nurse at first home visit (2-3 wks after birth); learn to discriminate hunger from other infant distress causes and alternate strategies to feeding as indiscriminate response to distress;

- Introduction to Solids only ( $n=29)$ : at first home visit (2-3 wks after birth) parents instructed to delay introduction of complementary foods until infant $\geq 4 \mathrm{mo}$; instructional handout on recognizing hunger and fullness cues; at second home visit (within 2 weeks of parents reporting infant was ready for solids), parents instructed on repeated exposure to improve acceptance of unfamiliar foods; guidance on recognizing hunger and fullness; after second visit parents were provided with pureed vegs to feed their infant (4 vegs; 1 veg for 6 consecutive days; 4 successive weeks)

- Soothe/sleep + Intro to solids: $(n=22)$ received both interventions

- No intervention (control) $n=30$ ): at first home visit, received standard infant parenting book; at second home visit, received standard AAP handout about introduction of solids; at both home visits, nurses answered questions on general infant care and breastfeeding

o In the INSIGHT trial (Savage, 2016) mother-infant dyads were randomized to 1 of 2 groups:

- "Responsive Parenting" Intervention ( $n=125)$ : Feeding component taught parents to recognize hunger, satiety cues, age-appropriate portion sizes and to use food for hunger only and not as a reward, punishment, or to soothe a distressed but not hungry child. Guidance included use of repeated exposure to promote acceptance of foods and beverages and the importance of modeling healthy eating behaviors, shared feeding responsibility, and establishing routines and limits. (Also included: ageappropriate sleep hygiene, emotional regulation, active social play, and growth chart education.)

- "Safety" Control ( $n=125)$ : received developmentally appropriate home safety intervention delivered by nurse home visitors; dosematched with RP group to ensure equivalent time and intensity; taught parents appropriate portion sizes, not to use food as a reward, non-food soothing techniques, and use of repeated exposure to increase acceptance of new foods.

- Observational studies

o Responsive feeding practices, including feeding on demand versus schedule: 6 papers (Gubbels, 2011; Ma, 2015; Morris, 1982; Saxon, 2002; Thompson, 2013; Worobey, 2009)

o Pressuring-to-eat: 8 papers (Dinkevich, 2015; Farrow, 2008; Gregory, 2011; Li, 2008; Lumeng, 2012; Ma, 2015; Thompson, 2013; Wright, 2006) 
o Restrictive feeding practices: 7 papers (Dinkevich, 2015; Farrow, 2008; Gregory, 2011; Hittner, 2016; Rifas-Shiman, 2011; Taveras, 2006; Thompson, 2013)

o Feeding in the absence of hunger or use food to soothe: 3 papers (Ma, 2015; Morris, 1982; Stifter, 2015)

o Indulgent feeding practices: 2 papers (Chaidez, 2014; Thompson, 2013)

o Caregiver concern about child weight and/or food intake: 2 papers (Dinkevich, 2015; Ma, 2015)

o Other:

- Baby-led weaning versus standard weaning: Brown, 2015

- Use of control (forcing, offering, positioning, or distracting the infant to eat): Farrow, 2006

- Monitoring (how much the mother keeps track of the amount of sweet, snack, and high-fat food her child eats): Farrow, 2008

- Modelling: Gregory, 2011

- Laissez-faire (parent does not limit infant diet quality or quantity and shows little interaction with the infant during feeding): Thompson, 2013

- Authoritative (offers structure, guidance, and positive modelling): Chaidez, 2014

o For bottle or breast feeding, studies examined bottle emptying (Li, 2008) and feeding to a schedule versus on demand (Gubbels, 2011; Saxon, 2002)

\section{Methods of exposure measurements in observation studies}

- Questionnaire: (16 papers)

o Child Feeding Questionnaire (CFQ):

- Farrow, 2008: monitoring, pressuring, restriction

- Gregory, 2011: pressuring, restriction

- Rifas-Shiman, 2011: restriction

- Taveras, 2006: restriction

o Food to Soothe Questionnaire (FTSQ): adapted from Baby's Basic Needs Questionnaire (BBNQ)

- Stifter, 2015: food to soothe

o Infant Feeding Questionnaire

- Dinkevich, 2015: pressuring, restriction, concern about infant overeating/weight, concern about undereating/underweight

o Infant Feeding Style Questionnaire

- Stifter, 2015: laissez-faire, pressuring, restrictive, responsive, indulgent

- Thompson, 2013: laissez-faire, pressuring/controlling, restrictive/controlling, responsive, indulgent

o Infant Feeding Practices Study (IFPS II)

- Li, 2008: encouragement of bottle emptying

o NCAST Feeding Scale

- Worobey, 2009: maternal sensitivity to infant cues

o Toddler Feeding Questionnaire 
- Chaidez, 2014: authoritative, indulgent

o Young Child Feeding Questionnaire

- Ma, 2015: concern about child undereating/underweight, concern about child overeating/overweight, interaction with child during feeding, overfeeding behavior, child's food preference, language communication during feeding, awareness of child's hunger and satiety cues, pushing child to eat more, using food to calm child, concern about child's food intake.

o Piloted questionnaire

- Saxon, 2002: feeding on demand versus scheduled feeding

o Questionnaire developed for the study

- Brown, 2015: baby-led versus standard weaning

- Gregory, 2011: modeling of healthy eating

- Gubbels, 2011: feeding on demand versus scheduled feeding

- Morris, 1982: recognition of hunger/satiety; feeding in the absence of hunger (questionnaire administered verbally by interviewer)

- Wright, 2006: maternal response to food refusal

- Observational measurement: (4 papers)

o Lab-based video/behaviors coded:

- Hittner, 2016: restrictive prompts

- During a 3 hour home visit, mother-child dyads were videotaped for $\sim 5$ min during a mealtime or snacking interaction. The child was fed in a highchair by parents who determined food/snack. The parents were not instructed on how to act and the mealtime was videotaped by research assistant 10 feet away with no interaction with dyad during feeding. Trained raters later coded the number of restrictive prompts by the mother in the observation.

- Lumeng, 2012: intrusion

- At child ages 15, 24, and 36 mo, mothers fed snacks to child in a lab; the sessions were videotaped and coded for 3 prompts: physical encouragements, verbal encouragements, and verbal offers. From these, 2 summary variables were created: total prompts (sum of all 3 prompt types) and percentage of assertive prompts (\% of total prompts that were verbal or phyical encouragements, as opposed to verbal offers).

- Mothers were coded as intrusive if they displayed any evidence of intrusiveness during the interactions; intrusiveness defines as maternal behavior that was adultcentered rather than child-centered, and imposed the mother's agenda on the child.

- Stifter, 2015: food to soothe

- Mothers and infants participated in lab-based tasks designed to elicit temperament (anger, fear, positivity) at infant ages 6, 12, and 18 mo. Each session videotaped and coded for parent soothing strategies. At age $18 \mathrm{mo}$, a snack tray was left in a room with mothers and infants 
during the lab visit. Mothers were told they could provide snacks. If mothers used food when child was fussing or crying then mother scored "yes" for using food to soothe.

o Home-based video/behaviors coded:

- Farrow, 2006: maternal use of control

- Mothers were observed feeding their infants solid foods at 6 mo of age in the home. The mothers were asked to feed their infants as normal with foods infant likes. The interaction was recorded by video camera from a nonobtrusive position.

- Maternal use of control during feeding was coded using the "nonverbal maternal behavior" scale from the Feeding Interaction scale (FIS).

\section{Feeding/food context}

- Feeding practices related to breast milk or formula feeding may have different considerations than feeding solids/complementary foods and beverages. While few papers mentioned the specific foods being consumed by the child during the study period, studies were categorized into breast milk/formula feeding and/or complementary foods and beverages at the time of the exposure assessment or intervention. This assignment was based on what was explicitly stated in the paper. In other words, categorization was not based on age or other factors.

o Breast milk only: 1 paper

- Controlled trial: De Carvalho, 1983

o Formula only: 1 paper

- Controlled trial: Kavanagh, 2008

o Breast milk/formula: 3 papers

- Cohort study: Gubbels, 2011, Li, 2008, Saxon, 2002

o Breast milk/formula and complementary foods and beverages: 13 papers

- Controlled trials: Daniels 2012, 2013, 2015; Machuca, 2016; Paul, 2011; Savage, 2016

- Cohort studies: Brown, 2015; Farrow, 2006; Stifter, 2015, Taveras, 2006; Thompson, 2013; Worobey, 2009; Wright, 2006;

o Complementary foods and beverages only: 8 papers

- Cohort studies: Chaidez, 2014; Dinkevich, 2015; Farrow, 2008; Gregory, 2011; Hittner, 2016; Lumeng, 2012; Ma, 2015; RifasShiman, 2011

o No indication: 1 paper

- Cohort study: Morris, 1982

\section{Outcome assessments}

- For this body of evidence, growth, size, and body composition were grouped and each study had to include at least one of these outcome measurements:

o Weight measures: weight, weight categories, weight-for-age z-scores or percentiles, weight-for-length/height z scores or percentiles, and weightfor-length/height categories 
o Change in weight measures: change in weight, rapid weight gain, conditional weight gain, change in weight-for-age, change in weight-forlength/height, and conditional weight gain scores

o BMI measures: BMI, BMI categories, BMI-for-age z-scores or percentiles

o Change in BMI measures: change in BMI and change in BMI-for-age zscores

o Skinfold thickness: measures of triceps skinfold thickness

\section{- Weight/Height/Body Composition Outcome Measures}

o Weight (W):

- Controlled Trials

- Daniels, 2013 (at 24 months)

- Kavanagh, 2008 (at $\sim 4$ months) (adjusted for baseline weight or length)

- Cohort Studies

- Saxon, 2002 (at 2, 4, and 6 months) (adjusted for birth weight)

o Weight for age z-score (WAZ):

- Controlled Trials

- Daniels, 2012 (at 14 months) (adjusted for baseline weight)

- Daniels, 2013 (at 24 months)

- Daniels, 2015 (at 14 months, 2, 3.5, and 5 years)

- Cohort Studies

- Thompson, 2013 (at 18 months) (adjusted for birth weight)

- Brown, 2015 (at $\sim 21$ months) (maternal report)

o "Standardized Weight" (WS):

- Cohort Studies

- Farrow, 2008 (at 2 years) (adjusted for baseline weight)

o Weight for height z-score (WHZ) or weight for length z-score (WLZ):

- Controlled Trials

- Paul, 2011 (at 4 months and 1 year) (adjusted for length measures)

- Savage, 2016 (at 1 year)

- Cohort Studies

- Dinkevich, 2015 (at 30 months) (adjusted for baseline weight)

- Gregory, 2011 (at 2 years) (adjusted for baseline weight) (maternal report)

o Height $(\mathrm{H})$ or Length $(\mathrm{L})$ :

- Controlled Trials

- Daniels, 2013 (L or H) (at $\sim 24$ months) 
- Kavanagh, 2008 (L) (at 4 months) (adjusted for baseline weight or length)

- Cohort Studies

- Saxon, 2002 (L) (at 2, 4, and 6 months) (adjusted for birth weight)

o Height-for-age z-score (HAZ):

- Controlled Trials

- Daniels, 2013 (at 24 months)

- Daniels, 2015 (at 14 months, 2, 3.5, and 5 years)

o Body mass index (BMI):

- Controlled Trials

- Daniels, 2013 (at $\sim 24$ months)

o Body mass index z-score (BMIz):

- Controlled Trials

- Daniels, 2012 (at 14 months) (adjusted for baseline weight)

- Daniels, 2013 (at 24 months)

- Daniels, 2015 (at 14 months, 2, 3.5, and 5 years)

- Cohort Studies

- Gubbels, 2011 (at 1, 2, and 4 years) (adjusted for birth weight) (parent report)

- Lumeng, 2012 (at 2 and 3 years) (adjusted for baseline weight)

- Rifas-Shiman, 2011 (at 3 years) (adjusted for baseline weight)

- Taveras, 2006 (at 3 years) (adjusted for birth measures)

o Overweight (Ow) and/or Obese (Ob):

- Controlled Trials

- Daniels, 2013 (Ow or Ob defined by BMI cutoffs from International Obesity Task Force) (at $~ 24$ months)

- Machuca, 2016 (Ow defined as BMI $\geq 85^{\text {th }} \%$ tile) (at 2 years) (adjusted for birthweight)

- Savage, 2016 (Ow defined as WLZ $\geq 95^{\text {th }} \%$ tile) (at 1 year)

- Cohort Studies

- Brown, 2015 (Ow /Ob defined as WAZ>85 $\%$ th $\%$ tile) (at $\sim 21$ months) (maternal report)

- Gubbels, 2011 (Ow defined as BMIz>85 \% \%tile) (at 1, 2, and 4 years) (adjusted for birth weight) (parent reported)

- Rifas-Shiman, 2011 (Ob defined as BMI $\geq 95$ th \%tile) (at 3 years) (adjusted for baseline weight) 
- Taveras, 2006 (Risk of Ow defined by BMIZ $\geq 85 \%$ tile and $<95 \%$ tile; Ow defined by BMIZ $\geq 95 \%$ tile) (at 3 years)

(adjusted for birth measures)

- Thompson, 2013 (High infant Weight defined as WAZ $>90 \%$ tile) (at 18 months) (adjusted for birth weight)

o Excess Weight (EW):

- Cohort Studies

- $\mathrm{Li}, 2008$ (EW defined as WAZ>1) (at 6 and 12 months) (adjusted for birth weight) (maternal report)

\section{- Changes in Weight/Height/Body Composition Outcome Measures}

o Weight gain (WG):

- Controlled Trials

- De Carvalho, 1983 (WG (g) from birth to 15 days and from birth to 35 days)

- Kavanagh, 2008 (WG (g per week) until 4 months of age) (adjusted for baseline weight or length)

- Cohort Studies

- Farrow, 2006 (WG [g, z-scores standardized for length and age] from 6 to 12 months)

- Worobey, 2009 (WG [kg]from 3 to 6 months and from 6 to 12 months) (adjusted for birth and baseline measures)

- Wright, 2006 (WG [standardized to UK 1990 growth reference] from birth to 12 months)

o Length gain (LG)

- Controlled Trials

- Kavanagh, 2008 (LG per week until 4 months of age) (adjusted for baseline weight or length)

o Rapid weight gain (RWG)

- Controlled Trials

- Daniels, 2012 (RWG defined as a change in WAZ of $>0.67$ which equates to the width of a percentile band on infant growth charts in children from birth to 13 months and from 4 to 13 months) (adjusted for baseline weight)

o Conditional weight gain (CWG)

- Controlled Trials

- Paul, 2011 (CWG defined as the standardized residuals from linear regression of 1 y WAZ on WAZ at time of intervention delivery, adjusted for sex in infants from $\sim 3$ weeks to 1 year) (adjusted for length measures)

- Savage, 2016 (CWG standardized residuals from the linear regression of weight for age at 28 weeks on weight for age 
at birth, with length for age at birth and 28 weeks and infant age at the 28-week assessment entered as covariates.

CWG $=0$ represents population mean; positive CWG: faster weight gain; Negative CWG: slower weight gain infants from birth to 6 months)

o Change in weight for height/length z-score $(\Delta \mathrm{WHZ} / \Delta \mathrm{WLZ})$

- Cohort Studies

- Chaidez, 2014 (Change in WHZ from 22 to 28 months) (adjusted for birth and baseline weight)

- Dinkevich, 2015 (Change in WLZ from 6 to 30 months)

- Stifter, 2015 (Change in WLZ from 6 to 12 months and from 6 to 18 months) (adjusted for birth weight)

0 Change in weight for age z-score ( $\triangle \mathrm{WAZ}$ )

- Cohort Studies

- Chaidez, 2014 (Change in WAZ from 22 to 28 months) (adjusted for birth and baseline weight)

- Gubbels, 2011 (WG [WAZ] from 0 to 12 months) (adjusted for birth weight) (parent reported)

0 Change in body mass index z-score $(\triangle B M I Z)$

- Cohort Studies

- Chaidez, 2014 (Change in BMIZ from 22 to 28 months) (adjusted for birth weight)

- Ma, 2015 (Change in BMIZ from 12 to 18 months in children that have a BMIZ>+1) (adjusted for birth weight)

0 Change in body mass index $(\triangle \mathrm{BMI})$

- Cohort Studies

- Hittner, 2016 (Change in BMI from 2 to 6 years) (years 5 and 6 were parent report)

- Skinfold Thickness Measures

o Tricep Skinfold (TR SF)

- Cohort Studies

- Morris, 1982 (at 9 months)

o Subscapular Tricep Skinfold (SS+TR SF)

- Cohort Studies

- Rifas-Shiman, 2011 (at 3 years) (adjusted for baseline weight)

- Taveras, 2006 (at 3 years) (adjusted for birth measures)

o Sum of Skinfold Thickness (Sum SF)

- Cohort Studies

- Thompson, 2013 (Sum SF thickness and categories defined by $>90 \%$ sum SF thickness) (at 18 months) (adjusted for birth weight) 
o Head Circumference

- Saxon, 2002 (at 2, 4, and 6 months) (adjusted for birth measures)

\section{Evidence synthesis}

This systematic review examined the relationship between caregiver feeding practices and weight outcomes in children from birth to two years old. This is a time of growth and development, and therefore caution should be used when interpreting findings related to higher or lower weight outcomes. Both inadequate weight gain and excessive weight gain are cause for concern during the period of development. Inadequate growth may signal failure to thrive while rapid weight gain increases risk for obesity and cardiometabolic disease. Therefore, associations suggesting that feeding practices are associated with higher or lower weight outcomes should be communicated carefully. This is important to emphasize for this study population of children two years and younger, where optimal results reflect "normal" weight gain and normal weight status, which is defined differently across the studies.

Inclusion and exclusion criteria, set a priori, limited this evidence to studies where the intervention or exposure included caregiver feeding practices and the outcomes reflected child growth, size, or body composition. However, the relationship between caregiver feeding practices and child's weight is not unidirectional. Many factors can influence caregiver feeding practices, including caregiver's perception and concern for their child's weight, the child's actual weight and health status, and the child's hunger and satiety signaling. To consider this complex relationship, two of the more recent observational studies in this body of evidence looked at the relationship between caregiver concern for child's weight, feeding practices, and child's weight. Ma (2015) reported that while caregivers of normal weight children were significantly more concerned about their children undereating or being underweight, caregivers of overweight children showed higher levels of concern about their children overeating or being overweight. Dinkevich (2015) found that mothers who were more concerned about their child overeating were more likely to exhibit restrictive feeding practices and were more likely to have a child with a higher weight-for-length z-score; conversely, mothers that were more concerned about their child undereating were more likely to pressure their child to eat and more likely to have a child with a lower weight-for-length z-score. Additionally, research beyond this body of evidence suggests that parental concern for child's weight can be influenced by cultural differences, and therefore study population/demographics should be considered when generalizing findings.

This body of evidence includes controlled trials and observational studies. Controlled trials are a stronger study design than observational studies and can provide evidence of a causal relationship between feeding practices and child weight outcomes. When reviewing the controlled trials within this body of evidence it is important to note that most interventions were multifaceted and included components that went beyond caregiver feeding practices as defined in this review. The cohort studies expand the evidence beyond responsive feeding and include several non-responsive feeding practices; however the dynamic relationship between feeding practices and child's weight should be considered when interpreting associations.

Table 2 provides a summary of the effects of (controlled trials) and associations between (observational studies) feeding practices and child weight outcomes. Table $\mathbf{3 a}$ and $\mathbf{3 b}$ provide an overview of each study. 


\section{Controlled trials}

Within the body of evidence, there were eight publications from controlled trials that examined the relationship between parental and caregiver feeding practices and growth, size, and body composition outcomes. This included four RCTs, one of which was the topic of three papers each with a different endpoint, and two non-randomized control trials. Two controlled trials were weighed less heavily (De Carvalho, 1983; Kavanagh, 2008) due to issues with directness of addressing the systematic review question and internal validity including high attrition, lack of statistical power, and inappropriate statistical measures.

The remaining four trials (Daniels [2012, 2013, 2015]; Paul, 2011; Savage, 2016; Machuca, 2016) were all multi-faceted interventions aimed to improve child eating habits and reduce weight gain by educating parents about infant feeding practices. Each trial had a component directed at teaching parents responsive feeding techniques, which is how to recognize and respond to hunger and satiety cues. Three interventions began when children were one month of age (Paul, 2011; Savage, 2016; Machuca, 2016) and one began when children were four months of age (Daniels [2012, 2013, 2015]), with outcome measurements ranging from 9 months after the intervention (Daniels, 2012) to 4.5 years after the invention (Daniels, 2015). All four trials were effective at influencing at least one of the weight outcomes; two of the trials were effective at reducing rapid weight gain at 13.5 months and 12 months of age, respectively (Daniels 2012; Savage, 2016); two trials were effective at reducing weight-for-length measures at 12 months of age (Paul, 2011, Savage, 2016); two trials reduced the prevalence of overweight status at 12 months and 24 months of age, respectively (Savage, 2016; Machuca, 2016); one study reduced weight-for-age and also BMI-for-age measures in intervention groups compared to control groups at 13.5 months of age (Daniels [2012, 2013, 2015]).

Paul (2011), from the SLIMTIME randomized controlled trial, tested the independent and combined effects of two behavioral interventions ( $2 \times 2$ factorial design). The interventions each included two home visits beginning two to three weeks after birth with the last follow-up when the child was one year old. The Soothe/Sleep intervention taught parents to discriminate hunger from other infant distress causes and included alternative strategies to feeding as an indiscriminate response to distress. The Introduction to Solids intervention instructed parents to delay complementary foods until infants were at least four months old. Parents were given instructional information on recognizing hunger and fullness cues, instructions on repeated exposure to improve acceptance of unfamiliar foods and were provided with pureed vegetables to feed their children. A third group received both interventions and the fourth group (control) received standard parenting advice. Children of parents who received the soothe/sleep intervention gained weight more slowly over the first year of life than those who did not receive that intervention. At one year of age, infants who received both interventions had a lower weight-for-length percentile than infants who received a single intervention or no intervention.

Savage (2016), from the INSIGHT randomized controlled trial, employed a responsive parenting intervention compared to a control group where parents received home safety information at home visits from nurses. The intervention began when infants were about four weeks old until they were 28 weeks with the last follow-up when the 
child was one year old. The intervention taught parents to recognize hunger and satiety cues and age-appropriate portion sizes. They were taught to only use food for hunger and not as a reward, punishment, or to soothe a distressed child. The intervention also included guidance on repeated exposure to promote acceptance of foods and beverages and the importance of modeling healthy eating behaviors. Infants in the intervention group gained weight less rapidly in the first six months of life, had a lower mean weight-for-length percentile at one year old, and had a lower prevalence of overweight status at one year than infants whose parents were in the control group.

One non-randomized controlled trial (Machuca, 2016) included an intervention for mother-infant dyads including standard care plus three, two-hour group sessions that included information on healthy nutrition and responsive feeding practices. Mothers were given a choice if they wanted to participate in the intervention; the control group, which was comprised of a subsample of those that chose not to participate in the intervention, received standard care. The intervention began when children were about one month old with the last follow-up when the child was two years old. The intervention included guidance on recognizing hunger and satiety cues, understanding how to avoid overfeeding, and using soothing techniques other than food. Participation in the intervention group reduced the likelihood of a child having a $\mathrm{BMI} \geq 85^{\text {th }}$ percentile at two years of age compared to those in the control group.

The three Daniels papers [2012, 2013, 2015] are from the NOURISH trial which consisted of an intervention for mother-infant dyads focused on healthy feeding practices when infants were four to six months old compared to a control group with self-directed access to usual community child health care. The intervention included two modules, each with six group sessions over three months, which focused on promotion of healthy food preferences, positive parenting, and encouragement of responsive feeding. Growth outcomes were assessed at 14 months, 2, 3.5, and 5 years old. Parental feeding practices were also assessed to measure the effect of the intervention on changes in behaviors and beliefs of parents in regard to feeding using the Infant Feeding Questionnaire (IFQ) (Daniels, 2012), Child Feeding Questionnaire (CFQ), Parental Feeding Style Questionnaire (PFSQ), and other clinically derived questions about responsive feeding (Daniels, 2013, 2015). At a nine month follow-up, when children were about 14 months old, the control group had greater weight-for-age z scores, greater BMI-for-age z-scores, and were more likely to show rapid weight gain from before the trial to the follow-up compared to the intervention group (Daniels, 2012). At a 20-month follow-up and 4.5 year follow-up, there were no significant effects of the intervention on growth indicators; however the intervention was effective at increasing maternal use of responsive feeding practices (Daniels, 2013, 2015). Intervention mothers reported fewer non-responsive feeding strategies (insisting their child eat, encouraging child with spoon/fork, offering food as reward) and greater responsive strategies (offering no food till next feed, accepting child may not be hungry) from 14 months to five years compared to mothers from the control group. Intervention mothers also reported less concern about child weight, less restriction, less pressure to eat, less instrumental feeding, greater encouragement, and less emotional feeding over time periods from 14 months to five years (Daniels, 2013, 2015).

The controlled trials by De Carvalho (1983) and Kavanagh (2008) are problematic due to certain limitations. De Carvalho (1983) was a non-randomized control trial with the purpose of investigating if more frequent feedings could increase breast milk 
production by comparing more frequent breastfeeding (on demand) to less frequent feedings (scheduled every 3-4 hours) on infant's weight at 15 days and 35 days of life. This study did not directly address the systematic review question and was not weighed heavily when constructing the conclusion statement. The purpose of the Kavanagh RCT was to test whether an intervention that educated formula-feeding mothers on responding to satiety cues during bottle feeding and limiting bottles to 6 ounces or less would result in less rapid weight gain compared to a control group. Results included differences in weight and length, however z-scores were not reported, therefore results are problematic to interpret. Additionally, this study had high attrition and was underpowered and therefore was not weighted heavily when constructing the conclusion statement.

\section{Cohort studies}

The body of evidence includes 19 publications from 17 cohorts. There are variations in the study methods including different exposures, outcome measurements, child age, and duration. The most prevalent feeding practices examined were responsive feeding, restrictive feeding, and pressuring to eat. Other studies examined feeding in the absence of hunger, the use of food to soothe, as well as controlling, monitoring, modeling, indulgent, and authoritative feeding practices. The outcomes for studies included in this review were a range of weight, growth, and/or body composition measures.

Six cohort studies examined the effect of responsive feeding practices on child weight and growth. One cohort study found that responsive feeding practices were associated with lower infant weight gain from six to 12 months, but no association with weight gain from three to six months (Worobey, 2009). Five studies found no association between responsive feeding practices and child weight, height, and/or head circumference (Morris, 1982; Saxon, 2002; Gubbels, 2011; Thompson, 2013; Ma, 2015). Among the studies that found no association, two examined the difference between infant feeding on demand versus feeding on a fixed schedule (Saxon, 2002; Gubbels, 2011).

Eight studies investigated the relationship between pressuring to eat and infant weight; five of these studies identified an association between the use of greater pressure and lower weight outcomes (Wright, 2006; Farrow, 2008; Li, 2008; Thompson, 2013; Dinkevich, 2015). Thompson, 2013 also found an association between greater pressure and lower skinfold thickness. Two studies found no significant association between pressuring to eat and infant weight (Gregory, 2011; Ma, 2016). Another study had mixed results (Lumeng, 2012). This study found that, before controlling for baseline weight, the number of times mothers prompted her child to eat was not associated with BMI Z-scores, but that the percentage of prompts considered as assertive or intrusive was associated with higher BMI z-scores. After controlling for initial weight, these associations were no longer significant.

Seven papers from six distinct cohorts looked at the relationship between restrictive feeding practices on child weight, size, and body composition outcomes. Four of these papers found at least one association between greater restrictive feeding practices and increased child weight measures (Taveras, 2006, Rifas-Shiman, 2011, Thompson, 2013, Dinkevich, 2015). One study found that greater restriction was associated with lower standardized weight scores (Farrow, 2008). Hittner, 2016 found a significant interaction between maternal restriction and child gender as a predictor of BMI change 
over time; for boys, greater restriction was associated with a lower BMI, but for girls, greater restriction was associated with a higher BMI. In Gregory, 2011 there was no association found between feeding restriction and child weight.

Three studies examined feeding in the absence of hunger or using food to soothe the infant. One study found that feeding to soothe was associated with greater weight gain from 6 to 18 months based on lab-based measures but no association was found when using parental report measures (Stifter, 2015). Two studies found no association between the use of food to soothe or feeding in the absence of hunger with weight (Ma, 2015) or body composition (Morris, 1982).

Two studies investigated indulgent feeding practices, practices that cater to the child and offer minimal structure. One study found an association between greater indulgent feeding practices and increased change in WAZ and BMI Z-scores (Chaidez, 2014), while another did not find a relationship between indulgent feeding and weight or body composition (Thompson, 2013).

Caregiver concern about child weight and/or food intake was studied in two cohorts. Dinkevich, 2015 found that maternal concern for child under-eating/weight was associated with lower weight status. Ma, 2015 found that concern for child food intake was associated with change in BMIz between 12 and 18 months of age in overweight children.

Several other feeding practices were only examined in one study, limiting the ability to assess consistency. One study (Brown, 2015) examined the association between baby-led weaning versus standard weaning and infant weight outcomes and found that baby-led weaning was associated with lower weight and less likelihood of being overweight than standard weaning. In another study, among mothers who were high in controlling behaviors measured at 6 months, 'control' was associated with infant weight gain from birth to six months and from six to 12 months (Farrow, 2006). Other feeding practices were not associated with child weight outcomes, these include: monitoring (how much the mother keeps track of the amount of sweet, snack, and high-fat food her child eats; Farrow, 2008), modelling (Gregory, 2011), laissez-faire practices (parent does not limit infant diet quality or quantity and shows little interaction with the infant during feeding; Thompson, 2013), and authoritative practices (offers structure, guidance, and positive modelling; Chaidez, 2014).

\section{Summary of cohort studies - in chronological order}

In the study by Morris (1982), a Virginia-based cohort examined the relationship between maternal feeding practices at three months and infant adiposity at nine months. Maternal feeding practices included the recognition of infant hunger and satiety cues, encouraging the infant to eat more once the infant stopped eating, feeding for non-hunger reasons, and feeding the infant one hour after eating. Infant adiposity was measured at nine months via triceps skinfold thickness. At the time the study was conducted there were few comparison groups with population measures of triceps skinfolds. The researchers examined differences in triceps skinfold between sexes in the study sample and compared the sample to a Swedish reference group; no differences were found. Other variables included in the analysis were the interaction of infant sex and maternal feeding practices and maternal attitudes to the food-related concepts of sweets/dessert, snacks/snacking, hunger, and food/eating. There were no significant relationships found between maternal feeding practices, the interaction of 
feeding practices and infant sex, or maternal attitudes towards food and infant adiposity at nine months.

Saxon (2002) examined feeding practices during early infancy prior to the initiation of complementary feeding in a cohort of infants in central Texas. In this study, the relationship between on-demand versus scheduled infant feeding and growth measures that included head circumference, body length, and weight was explored. Infant feeding was categorized into four methods: exclusively breast fed, exclusively formula fed, primarily breast fed with some formula, and primarily formula fed with some breast feeding. Growth measures were collected at birth, two, four, and six. When controlling for the baseline growth measures, no differences were found in growth measures between on-demand versus scheduled feeding in the infants at two, four, or six months of age.

Maternal control during feeding was examined as a moderator of infant weight gain from birth to 12 months in a UK-based cohort (Farrow, 2006). The investigators assessed maternal feeding practices during an observed feeding interaction at infant age six months. The controlling behaviors that were assessed during the interaction were, for the highest degree of control, continuously forcing, offering, positioning, or distracting the infant to eat. For the behaviors that demonstrated the lowest degree of control, infant feeding was supervised by the mothers and allowed the infant autonomy to control their own feeding. The study found that maternal control moderated the relationship between infant weight gain from birth to six months and six to 12 months. When maternal control was moderate or low, infants with rapid weight gain from birth to six months tended to have slower weight gain from six to 12 months whereas those with slower weight gain from birth to six months tended to accelerate their weight gain from six to 12 months. No association was found between high maternal control and infant weight gain.

Maternal feeding restriction was examined as a moderator between breast feeding and child overweight at three years of age in a cohort of children from urban and suburban eastern Massachusetts enrolled in Project Viva (Taveras, 2006). Breast feeding and feeding restriction was assessed at 12 months via maternal report and at three years the child's weight status was measured via BMI and skinfolds (subscapular and triceps). At three years, maternal feeding restriction at one year had a positive association with BMI z-score and the odds of being at risk of overweight but no association with subscapular plus triceps skinfold or the odds of being overweight at three years old.

Wright (2006) examined the influence of maternal feeding practices in response to food refusal at eight months and infant weight gain in the first year of life among children enrolled in Gateshead, UK. In this study, the four related feeding practices employed by mothers in response to child food refusal were: encouraged the child to eat, offered alternative food, offered the same food later, and made the child eat. The frequency of utilization of these feeding practices was categorized from rarely $(0)$ to often (4). Maternal response to food refusal at eight months was significantly related to weight gain at one year, such that a higher level of utilization of these practices in response to food refusal resulted in lower weight gain.

In a study by Farrow (2008), pressuring to eat and feeding restriction at one year were examined in relation to child weight at two years in the UK. Maternal feeding practices were measured via questionnaire and included, in addition to pressuring and 
restriction, monitoring. In this study, monitoring was considered the degree to which the mother keeps track of the amount of sweet, snack, and high-fat foods consumed by the child. It was found that both pressuring to eat and restriction at one year had a negative correlation with weight at two years; monitoring did not have an association with weight. The relationships remained constant when controlling for weight at one year.

Li (2008) explored the association between mother's encouragement of bottle emptying and the infant's risk for excess weight and was based in a nationally representative sample in the Infant Feeding Practice Study (IFPS II). When infants were one month old, a maternal self-administered questionnaire assessed encouragement of bottle emptying by asking the mother how often they encouraged the baby to finish a bottle if the baby stopped drinking before the bottle was finished. Child weight was also reported by mothers via questionnaire when infants were three, five, seven, and 12 months old. In unadjusted bi-variate analyses, no association was found between encouragement of bottle emptying and the mean difference between infants who had excess weight and those who did not have excess weight during the second half of infancy. After controlling for a sociodemographic characteristics, maternal health, and other infant feeding practices using multiple logistic regression, infants who were sometimes or often encouraged to empty their bottles were significantly less likely to have excess weight (measured by a weight-for-age z-score that is greater than 1) compared to infants who were rarely encouraged to empty their bottles.

In a cohort of mother-infant dyads recruited from a WIC center, Worobey (2009) found that maternal sensitivity to infant cues when the infant was 3 months was associated with lower infant weight gain from 6 to 12 months, while there was no association from 3 to 6 months. The study controlled for several factors. In the model examining weight gain from 3 to 6 months, analyses controlled for birth weight, infant weight and length gain from birth to 3 months, the estimated number of feeds per day at 3 months, and the month that solid foods were introduced. In the models for weight gain from 6 to 12 months, analyses controlled for birth weight, infant weight and length gain from 3 to 6 months and the estimated number of feeds per day at 6 months.

Pressuring to eat and restriction at one year was examined in relation to child weight at two years in an Australian cohort by Gregory (2011). In this study, maternal feeding practices were assessed via questionnaire and child weight at two years was modeled using weight-for-height z-score (WHZ). A third feeding practice-related behavior, maternal modeling of healthy eating, was measured via maternal report of the consumption of healthy foods and unhealthy fast foods, in front of their child. The results showed no association between restriction, pressuring, or modeling at one year and child weight status at two years.

The association between scheduled versus feeding on demand and weight gain through four years among breast fed infants was explored in a Dutch cohort in Gubbels (2011). A maternal questionnaire was used to if infants were being fed on demand or fed according to a fixed schedule when infants were three months old. Growth measures were collected when children were one, two, and four years old. Feeding to a schedule at three months was not associated with weight gain from birth to one year or child BMI or overweight status at one, two, or four years when compared to infants who were fed on demand. 
In the Rifas-Shiman (2011) study the Project Viva cohort was investigated to explore the relationship between feeding restriction at one year and weight status measured via BMI and skinfolds (subscapular and triceps) at three years. The investigators further examined the degree to which this association was explained by weight for length (WFL) at one year and maternal pre-pregnancy weight status. A secondary analysis studied the association between restriction at six months and BMI at three years. The study found that restriction at one year was positively associated with BMI, skinfold thickness, and the likelihood of children being categorized as obese at three years, however, the associations were not significant after controlling for weight for length at one year. Similarly, restriction at six months was positively associated with children's BMI at three years, but not after accounting for six month WFL. Maternal pre-pregnancy BMI did not modify the relationship between restriction at one year and children's BMI z-scores at three years.

The study by Lumeng (2012) included mothers and children enrolled in the NICHD Study of Early Child Care and Youth Development to examine the association between maternal prompts to eat, assertive prompts to eat, and intrusive prompts to eat and child adiposity. In a lab setting, when children were 15, 24, and 36 months old, mothers were videotaped feeding snacks to their child. Three different maternal prompts were recorded: physical encouragements, verbal encouragements, and verbal offers. Total prompts were considered as a sum of all three types of prompts; Assertive prompts were considered the percentage of total prompts that were verbal or physical encouragement. Mothers were considered intrusive if they displayed any behavior during the interaction that was adult-centered rather than child-centered. At these same lab visits, child weight and length were measured and weight-for-length a scores and BMI z-scores were collectively referred to as adiposity z-scores. While total number of prompts was not associated with BMIz across the duration of the study, the percentage of maternal assertive prompts and intrusiveness, both alone and in combination, was associated with increased BMIz. However, when controlling for adiposity at $15 \mathrm{mo}$, percentage of assertive prompts or maternal intrusiveness were not predictive of child adiposity or overweight at age $36 \mathrm{mo}$.

A cohort of first-time African-American mothers in central North Carolina was studied to examine the relationship between 13 sub-constructs of five feeding practices and infant weight and adiposity from ages three to 18 months (Thompson, 2013). Five categories of feeding practices were examined: (1) laissez-faire (LF) where the parent does not limit infant diet quantity or quality and has little interaction during feeding; (2) pressuring/controlling (PR) where the parent focuses on increasing the infant's food intake; (3) restrictive/controlling (RS) where the parent focuses on decreasing the infant's food intake; (4) responsive feeding (RP) where the parent responds to the infant's hunger and satiety cues; and (5) indulgent (IN) characterized by the lack of limit-setting. Thirteen sub-constructs for the categories were investigated: LF-attention; LF-diet quality; PR-finish; PR-cereal; PR-soothing; RS-amount; RS-diet quality; RPsatiety; RP-attention; IN-permissive; IN-coaxing; IN-soothing; IN-pampering. Infant weight and skinfold thickness (sum of subscapular, triceps, and abdominal) were assessed at three, six, nine, 12, and 18 months. Lagged longitudinal models were used to examine the relationship between the sub-constructs and infant size at the next study visit. The sub-constructs PR-finish (pressuring to finish food) predicted lower WAZ at the next study visit, PR-cereal (pressuring to increase food intake via cereal) predicted lower skinfold thickness at the next visit, and RS-diet quality (restricting the infant diet in regards to quality of foods) predicted higher WAZ at the 
next visit. The other ten sub-constructs were not associated with infant weight or adiposity.

The association between indulgent and authoritative feeding practices and anthropometry was investigated in Northern Californian toddlers (Chaidez, 2014). In this study, indulgent feeding practices were defined as practices that catered to the child and offered little to no structure, guidance, or limit-setting. Authoritative feeding practices were defined as practices that offered structure, guidance, and positive modeling of eating behaviors. Toddler anthropometry, including weight-for-height, weight-for-age, BMI z-score, as well as change in weight and BMI z-score, was measured at approximately 22 months of age for baseline and approximately 28 months of age at follow-up. Indulgent feeding practices were positively associated with anthropometric indicators of toddler weight status; there were no associations with authoritative feeding practices.

Infant autonomy during feeding was examined in a study of weaning style from South West Wales in the UK (Brown, 2015). This study examined the association of baby-led weaning versus standard weaning from 6 to 12 months of age and infant weight at 18 to 24 months of age. Child weight was collected via maternal report. In baby-led weaning, infants who are complementary feeding are presented with whole foods at feeding times and self-select, grasp, bring to mouth, and consume foods autonomously. Maternal control of feeding is minimal and the infant decides which food item is selected and the quantity and speed of consumption. Baby-led weaners in this study were mothers who reported using spoon feeding and purees $10 \%$ of the time or less whereas standard weaners were those that reported using spoon feeding and purees more than $10 \%$ of the time. The results of the study showed that mothers who practiced baby-led weaning had infants who weighed less and were less likely to be overweight at both baseline and end of follow-up. In addition, mothers who practiced baby-led weaning reported lower levels of concern for their infant's weight, pressure to eat, restriction, and monitoring than standard weaners, however, there was no difference between groups in perceived responsibility.

The association between restrictive feeding and pressuring to eat at six to 12 months of age and child weight through 30 months was assessed in a New York City-based cohort of mother-infant dyads in Dinkevich (2015). Feeding practices were assessed at baseline (when the infants had a mean age of approximately nine months) via questionnaire and child weight and length were abstracted from the medical records of well-child visits through 30 months. In this study, higher maternal food restriction was associated with higher infant WLZ while higher pressuring was associated with lower infant WLZ. Maternal concern for child under-eating/weight was positively associated with WLZ; however, infant's initial weight was found to be the strongest predictor of future weight gain.

A Shanghai-based study by $\mathrm{Ma}$ (2015) investigated the relationship between caregivers' feeding attitudes and behaviors and infants' weight status. The caregivers of this sample had a unique composition. While the caregivers of the other studies included in this review were almost exclusively mothers, in this sample $32 \%$ were parents, $37 \%$ grandparents, $30 \%$ parents and grandparents, and $1 \%$ others. Ten factors related to caregivers' feeding attitudes and behaviors were examined when the infant was 6, 12, and 18 months old: concern about the child's food intake, concern about the child undereating or underweight, concern about the child overeating or overweight, interaction with the child during feeding, overfeeding behavior, the child's 
food preference, language communication during feeding, awareness of the child's hunger and satiety cues, pushing the child to eat more, and using food to calm the child. The only significant association found was a relationship between concern about the child's food intake in overweight children and change in BMI-for-age z-score between 12 and 18 months of age after controlling for birth weight and mother's prepregnancy height.

Stifter (2015) investigated the relationship between the use of food to soothe and infant weight in cohort from central Pennsylvania. Lab observation of maternal-infant interaction and maternal interview at ages six, 12, and 18 months were utilized to assess food to soothe feeding practices. Change in infant weight from six to 18 months was positively associated with lab observed feeding to soothe practices at six months. Lab observations at 12 and 18 months and maternal reports of the use of food to soothe from six to 18 months were not associated with change in infant weight at any of the ages examined.

A secondary analysis by Hittner (2016) from the Colorado Adoption Project (CAP) examined the relationship between maternal restriction, observed during a five minute videotaped feeding interaction at a home visit when the infant was one year old, and the prediction of BMI gain through six years of age. The CAP includes data on both adopted and non-adoptive families that are matched on infant sex, number of siblings, and paternal age, occupational status, and education. For children who were adopted, the study includes information on bother their biological and adoptive parents. Maternal restriction was measured as any attempt by the mother, either physically or verbally, to prevent the infant from reaching for a spoon or putting food to their mouth. Child weight and length were assessed every year from when infants were two to six years old. Between ages two through four these measurements were taken by a researcher; at five and six years, weight and height were attained via parental report. After controlling for maternal BMI, infant age at year one, and infant adoption status, there was a significant interaction between infant sex and maternal restriction during a single eating occasion with a one year old child on predicting child BMI change over time from one year to six years old. For boys, some or moderate restriction was associated with a decline in BMI from ages two through six years and for girls whose mothers showed any restriction demonstrated BMI increases during that time compared to mothers who showed no restriction.

\section{Assessment of the body of evidence}

This body of evidence was deemed to be moderate in strength due to:

- Internal validity (determined with NEL Bias Assessment Tool): Two controlled trials had limited internal validity (De Carvalho, 1983, Kavanagh, 2008) related to directness and sample size/power. The cohort studies had many limitations related to internal validity, particularly problematic was the use of parental report for exposure and outcome data in several studies.

- Consistency: The four strongly designed controlled trials showed a consistent effect of multicomponent interventions that include responsive feeding practices on child weight outcomes following the intervention. There was some consistency in the findings from cohort studies that examined controlling feeding practices. Some other feeding practices were only examined in a single study which limits the ability to assess consistency. 
- Impact: While changes in weight outcomes may be small, they were significant and are important from a public health perspective. Because children are growing there would be a concern if an intervention led to a large decrease in weight or growth compared to a control group.

- Adequacy: There were only four strong controlled trials from three independent research groups. There were seventeen cohort studies.

- Generalizability: Three of the four strong controlled trials are with mostly white, middle-class, college-educated women. One of those studies (Daniels, 2012, 2013,2015 ) has an Australian population. One study (Machuca, 2016) is in an urban, high poverty, predominantly minority population. Four cohort studies focus on underserved populations (Chaidez, 2014; Dinkevich, 2015; Thompson, 2013; Worobey, 2009), however the majority of cohort study participants are white, educated women.

- Other limitations/considerations: In addition to the limitations noted with internal validity, the body of evidence has several inconsistencies in methodology including the interventions, exposures, outcomes, child age, and time to follow-up. The stability of feeding practices is unknown, particularly during the transition from breast or bottle-feeding to feeding complementary foods and beverages. As mentioned earlier, the relationship between caregiver feeding practices and child weight outcomes is bidirectional, yet another factor in that relationship is the child's signaling, i.e. the child's own recognition of hunger and satiety and how that is expressed. 


\section{Table 2. Overview of associations between feeding practices and child weight outcomes}

\begin{tabular}{|c|c|c|c|c|}
\hline $\begin{array}{l}\text { Study } \\
\text { Design/ } \\
\text { Article }\end{array}$ & Exposure & & Outcomes & \\
\hline $\begin{array}{l}\text { Controlled } \\
\text { Trials }\end{array}$ & $\begin{array}{l}\text { Feeding } \\
\text { Practice }\end{array}$ & Weight/Height/Body Composition & Change in Weight/Height/Body Composition & Skinfold thickness \\
\hline Daniels, 2012 & $\begin{array}{l}\text { Responsive } \\
\text { feeding }\end{array}$ & $\begin{array}{l}\text { BMIZ*: Children whose parents received the } \\
\text { responsive feeding intervention had lower BMIz } \\
\text { scores at } 13 \text { mo old compared to children whose } \\
\text { parents did not receive the intervention. } \\
\text { NS: WAZ* }\end{array}$ & $\begin{array}{l}\text { RWG* (from birth to } 13 \text { mo and from } 4 \text { to } 13 \text { mo of } \\
\text { age): Children whose parents received the } \\
\text { responsive feeding intervention had less rapid } \\
\text { weight gain from birth to } 13 \text { mo and from } 4 \text { to } 13 \\
\text { mo of age compared to children whose parents did } \\
\text { not receive the intervention. }\end{array}$ & \\
\hline Daniels, 2013 & & $\begin{array}{l}\text { NS: W; WAZ; H; HAZ; BMI; BMIZ; Ow/Ob (BMI } \\
\text { cutoffs from International Obesity Task Force) }\end{array}$ & & \\
\hline Daniels, 2015 & & NS: WAZ; HAZ; BMIZ & & \\
\hline $\begin{array}{l}\text { Machuca, } \\
2016\end{array}$ & $\begin{array}{l}\text { Responsive } \\
\text { feeding }\end{array}$ & $\begin{array}{l}\text { Ow* (BMI } \geq 85^{\text {th }} \% \text { tile): Children whose parents } \\
\text { received the responsive feeding intervention were } \\
\text { less likely to be overweight at } 2 \text { y old compared to } \\
\text { children whose parents did not receive the } \\
\text { intervention. }\end{array}$ & & \\
\hline Paul, 2011 & $\begin{array}{l}\text { Responsive } \\
\text { feeding }\end{array}$ & $\begin{array}{l}\text { WLZ*: Children whose parents received the } \\
\text { Soothe/sleep + Intro to Solids intervention had lower } \\
\text { WLZ at } 1 \text { y old compared to children whose parents } \\
\text { did not receive both interventions. }\end{array}$ & $\begin{array}{l}\text { CWG: Children whose parents received the } \\
\text { Soothe/sleep intervention had gained weight slower } \\
\text { from } \sim 3 \mathrm{w} \text { to } 1 \text { y old compared to children whose } \\
\text { parents did not receive this intervention. } \\
\text { NS: IWG }\end{array}$ & \\
\hline Savage, 2016 & $\begin{array}{l}\text { Responsive } \\
\text { feeding }\end{array}$ & $\begin{array}{l}\text { WLZ*; Ow (WLZ } \geq 95^{\text {th }} \% \text { tile): Children whose parents } \\
\text { received the responsive feeding intervention had } \\
\text { lower WLZ scores and were less likely to be } \\
\text { overweight at } 1 \text { y old compared to children whose } \\
\text { parents did not receive the intervention. }\end{array}$ & $\begin{array}{l}\text { CWG: Children whose parents received the } \\
\text { responsive feeding intervention gained weight } \\
\text { slower from birth to } 6 \text { mo old compared to children } \\
\text { whose parents did not receive the intervention. }\end{array}$ & \\
\hline
\end{tabular}




\begin{tabular}{|c|c|c|c|c|}
\hline $\begin{array}{l}\text { Study } \\
\text { Design/ } \\
\text { Article }\end{array}$ & Exposure & & Outcomes & \\
\hline \multirow[t]{2}{*}{$\begin{array}{l}\text { De Carvalho, } \\
1983^{+}\end{array}$} & $\begin{array}{l}\text { Responsive } \\
\text { feeding/ } \\
\text { restriction }\end{array}$ & & $\begin{array}{l}\text { WG: Children whose mothers were told to } \\
\text { breastfeed per schedule, every } 3-4 \text { hrs, gained less } \\
\text { weight from birth to } 15 \text { days old compared to } \\
\text { children whose mothers fed on demand (more } \\
\text { frequently than the scheduled feeders). }\end{array}$ & \\
\hline & & & NS: WG (birth to $35 \mathrm{~d}$ ) & \\
\hline $\begin{array}{l}\text { Kavanagh, } \\
2008^{+}\end{array}$ & $\begin{array}{l}\text { Responsive } \\
\text { feeding }\end{array}$ & $\begin{array}{l}W^{*} ; L^{*} \text { : Children whose parents received the } \\
\text { responsive feeding intervention had higher weight } \\
\text { and length measures at } 4 \text { mo of age compared to } \\
\text { children whose parents did not receive the } \\
\text { intervention. }\end{array}$ & $\begin{array}{l}\text { WG* (per week); LG* (per week): Children whose } \\
\text { parents received the responsive feeding } \\
\text { intervention had gained more weight and grew } \\
\text { more in length per week compared to children } \\
\text { whose parents did not receive the intervention. }\end{array}$ & \\
\hline $\begin{array}{l}\text { Cohort } \\
\text { Studies }\end{array}$ & $\begin{array}{l}\text { Feeding } \\
\text { Practice }\end{array}$ & Weight/Height/Body Composition & Change in Weight/Height/Body Composition & Skinfold thickness \\
\hline Brown, 2015 & Baby-led v Std & $\begin{array}{c}\left.\text { WAZ; Ow/Ob (WAZ }>85^{\text {th }} \% \text { tile) }\right)^{*} \text { The use of baby-led } \\
\text { weaning was associated with lower weight and less } \\
\text { likelihood of being overweight or obese at } 21 \text { mo old } \\
\text { compared to those who used standard weaning } \\
\text { practices. }\end{array}$ & & \\
\hline \multirow[t]{2}{*}{ Chaidez, 2014} & Indulgent & & $\begin{array}{c}\Delta \mathrm{WHZ}^{*} ; \triangle \mathrm{WAZ}^{*} ; \triangle \mathrm{BMIZ} * \text { : Indulgent parental } \\
\text { feeding practices were associated with greater } \\
\text { changes in child's WHZ, WAZ, and BMIZ from } \\
\text { baseline ( } 22 \mathrm{mo} \text { old) to } 6-\mathrm{mo} \text { follow-up ( } 28 \mathrm{mo} \\
\text { old). }\end{array}$ & \\
\hline & Authoritative & & NS: $\Delta \mathrm{WHZ}^{*} ; \Delta \mathrm{WAZ}^{*} ; \Delta \mathrm{BMIZ}^{*}$ & \\
\hline \multirow[t]{3}{*}{$\begin{array}{l}\text { Dinkevich, } \\
2015\end{array}$} & Restriction & $\begin{array}{l}\text { WLZ*: Restrictive feeding practices were associated } \\
\text { with higher WLZ in children between the ages of } 6 \text { to } \\
\qquad 30 \mathrm{mo} \text {; }\end{array}$ & NS: $\Delta \mathrm{W}^{*}$ (from $6 \mathrm{mo}$ to $30 \mathrm{mo}$ ) & \\
\hline & Pressure & $\begin{array}{l}\text { WLZ*: Pressuring to eat was associated with lower } \\
\text { WLZ in children between the ages of } 6 \text { to } 30 \mathrm{mo} \text {; }\end{array}$ & NS: $\Delta W^{*}$ (from 6 mo to $30 \mathrm{mo}$ ) & \\
\hline & $\begin{array}{l}\text { Concern } \\
\text { under/ovwt }\end{array}$ & $\begin{array}{l}\text { WLZ*: Concern for undereat/wt was associated with } \\
\text { greater WLZ; }\end{array}$ & $\begin{array}{c}\Delta \mathrm{W}^{*}: \text { Concern for overeat/wt was a significant } \\
\text { predictor of future weight gain }\end{array}$ & \\
\hline
\end{tabular}




\begin{tabular}{|c|c|c|c|}
\hline $\begin{array}{l}\text { Study } \\
\text { Design/ } \\
\text { Article }\end{array}$ & Exposure & & Outcomes \\
\hline Farrow, 2006 & Control & & $\begin{array}{l}\text { There was an interaction between the degree of } \\
\text { maternal controlling behaviors measured at } 6 \text { mo } \\
\text { and infant weight gain from } 0 \text { to } 6 \text { months on infant } \\
\text { weight gain from } 6 \text { to } 12 \text { mo. }\end{array}$ \\
\hline \multirow[t]{3}{*}{ Farrow, 2008} & Restriction & $\begin{array}{l}\text { WS*: The use of maternal restrictive feeding when } \\
\text { child was } 1 \text { year old predicted lower weight at age } 2 \text {, } \\
\text { even when controlling for weight at age } 1 \text {; }\end{array}$ & \\
\hline & Pressure & $\begin{array}{l}\text { WS*: The use of maternal pressuring to eat when } \\
\text { child was } 1 \text { year old predicted lower weight at age } 2 \text {, } \\
\text { even when controlling for weight at age } 1 \text {; }\end{array}$ & \\
\hline & Monitoring & NS: WS* & \\
\hline \multirow{3}{*}{$\begin{array}{l}\text { Gregory, } \\
2011\end{array}$} & Restriction & NS: WHZ* & \\
\hline & Pressure & NS: WHZ* & \\
\hline & Modeling & NS: WHZ* & \\
\hline $\begin{array}{l}\text { Gubbels, } \\
2011\end{array}$ & $\begin{array}{l}\text { Responsive } \\
\text { feeding } \\
\text { (Demand vs } \\
\text { Schedule) } \\
\end{array}$ & NS: BMIZ*; Ow* (BMIZ > 85th \%tile) & NS: WG* \\
\hline \multirow[t]{2}{*}{ Hittner, 2016} & Restriction & & $\Delta \mathrm{BMI} \&$ gender interaction*: \\
\hline & & & $\begin{array}{l}\text { There was a significant interaction between } \\
\text { maternal restriction at } 1 \text { yr and child gender on } \\
\text { predicting child BMI change from } 2 \text { to } 6 \text { y old. In } \\
\text { boys, some or moderate (vs no) restriction was } \\
\text { associated with a decrease in BMI from } 2 \text { to } 6 \text { y old. } \\
\text { In girls, some or moderate (vs no) restriction was } \\
\text { associated with an increase in BMI from } 2 \text { to } 6 \text { y old. }\end{array}$ \\
\hline Li, 2008 & Pressure & $\begin{array}{c}\text { Odds of WAZ>1*: Infants who were sometimes or } \\
\text { often encouraged to empty their bottles at } 1 \text { mo old } \\
\text { were less likely to have excess weight from } 6 \text { to } 12 \\
\text { mo of age. }\end{array}$ & \\
\hline
\end{tabular}




\begin{tabular}{|c|c|c|c|c|}
\hline $\begin{array}{l}\text { Study } \\
\text { Design/ } \\
\text { Article }\end{array}$ & Exposure & \multicolumn{3}{|c|}{ Outcomes } \\
\hline \multirow[t]{2}{*}{ Lumeng 2012} & Pressure & $\begin{array}{l}\text { BMIZ (\% assertive prompts \& \% intrusive prompts, } \\
\text { not controlling for wt): The percentage of maternal } \\
\text { assertive prompts and intrusiveness at } 15 \text { mo, both } \\
\text { alone and in combination, was associated with higher } \\
\text { BMIz at } 36 \text { mo of age. }\end{array}$ & & \\
\hline & & $\begin{array}{l}\text { NS: BMIZ* (total prompts; \% assertive } \& \text { intrusive } \\
\text { prompts when controlling for wt) }\end{array}$ & & \\
\hline \multirow[t]{5}{*}{ Ma, 2015} & $\begin{array}{l}\text { Responsive } \\
\text { feeding }\end{array}$ & & NS: $\triangle B M I * 12-18$ mo in Ow children (BMIZ>+1) & \\
\hline & Pressure & & NS: $\triangle B M I Z^{*} 12-18 \mathrm{mo}$ in Ow children (BMIZ>+1) & \\
\hline & Food to Soothe & & NS: $\triangle B M I Z * 12-18$ mo in Ow children (BMIZ>+1) & \\
\hline & $\begin{array}{l}\text { Concern about } \\
\mathrm{Wt}\end{array}$ & & NS: $\triangle B M I Z * 12-18$ mo in Ow children $(B M I Z>+1)$ & \\
\hline & $\begin{array}{l}\text { Concern about } \\
\text { Intake }\end{array}$ & & $\begin{array}{l}\triangle \mathrm{BMIZ} * 12-18 \text { mo in Ow children (BMIZ>+1): In } \\
\text { overweight children, concern about child's food } \\
\text { intake was correlated with an increase in BMIZ } \\
\text { between } 12 \text { and } 18 \text { months. }\end{array}$ & \\
\hline \multirow[t]{2}{*}{ Morris, 1982} & $\begin{array}{l}\text { Responsive } \\
\text { feeding }\end{array}$ & & & NS: TR SF \\
\hline & $\begin{array}{l}\text { Feeding } \\
\text { absence } \\
\text { hunger }\end{array}$ & & & NS: TR SF \\
\hline \multirow[t]{4}{*}{$\begin{array}{l}\text { Rifas-Shiman, } \\
2011\end{array}$} & Restriction & $\begin{array}{l}\text { Before adj for wt: BMIZ; Ob (BMI } \geq 95 \text { th } \% \text { tile): } \\
\text { Maternal feeding restriction at } 1 \mathrm{y} \text { was associated } \\
\text { with children having a higher BMI and greater } \\
\text { likelihood of being categorized as obese at age } 3 \text {, } \\
\text { before controlling for WFLZ at } 1 \mathrm{y} \text {. }\end{array}$ & & $\begin{array}{l}\text { Before adj for wt: SS+TR } \\
\text { SF: Maternal feeding } \\
\text { restriction at age } 1 \text { was } \\
\text { associated with children } \\
\text { having greater skinfold }\end{array}$ \\
\hline & & NS: After adj for wt: BMIZ*; Ob* (BMI $\geq 95$ th \%tile) & & $\begin{array}{c}\text { measures at age } 3 \text {, before } \\
\text { controlling for WFLZ at } 1\end{array}$ \\
\hline & & & & $\mathrm{y}$ \\
\hline & & & & $\begin{array}{l}\text { NS: After adj for wt: SS+TR } \\
\text { SF* }\end{array}$ \\
\hline
\end{tabular}




\begin{tabular}{|c|c|c|c|c|}
\hline $\begin{array}{l}\text { Study } \\
\text { Design/ } \\
\text { Article }\end{array}$ & Exposure & & Outcomes & \\
\hline Saxon, 2002 & $\begin{array}{l}\text { Responsive } \\
\text { feeding }\end{array}$ & NS: $W^{*} ; L^{*}$ & & \\
\hline \multirow[t]{2}{*}{ Stifter, 2015} & Food to Soothe & & $\begin{array}{l}\text { WG* } 6 \text { to } 18 \text { mo (Lab-observed): There was an } \\
\text { association with using food to soothe at } 6 \text { mo and a } \\
\text { greater change in weight from } 6 \text { to } 18 \text { mo compared } \\
\text { to those who did not use food to soothe based on } \\
\text { lab observation. }\end{array}$ & \\
\hline & & & $\begin{array}{c}\text { NS: WG* } 6 \text { to } 18 \text { mo (Parent report); WG* } 6 \text { to } 12 \\
\text { mo (Lab-observed, Parent report) }\end{array}$ & \\
\hline \multirow[t]{2}{*}{ Taveras, 2006} & Restriction & $\begin{array}{l}\text { BMIZ*; Risk of Ow* (BMIZ } \geq 85 \% \text { tile and }<95 \% \text { tile): } \\
\text { Use of maternal feeding restriction at } 1 \text { y was } \\
\text { significantly associated with a higher BMIZ and } \\
\text { higher odds of being at risk of overweight at } 3 y \text {. }\end{array}$ & & NS: SS +TR SF* \\
\hline & & NS: $O w^{*}$ (BMIZ $\geq 95 \%$ tile) & & \\
\hline \multirow[t]{6}{*}{$\begin{array}{l}\text { Thompson, } \\
2013\end{array}$} & $\begin{array}{l}\text { Responsive } \\
\text { feeding }\end{array}$ & NS: WAZ*; >90\% WAZ* & & $\begin{array}{l}\text { NS: sum SF thickness*; } \\
>90 \% \text { sum SF thickness* }\end{array}$ \\
\hline & Restriction & $\begin{array}{l}\text { WAZ*: The use of restriction at } 3 \text { mo was associated } \\
\text { with higher WAZ at } 3,6,9,12,18 \text { mo of age }\end{array}$ & & $\begin{array}{l}\text { NS: sum SF thickness*; } \\
>90 \% \text { sum SF thickness* }\end{array}$ \\
\hline & & NS: $>90 \%$ tile WAZ* & & \\
\hline & Pressure & $\begin{array}{l}\text { WAZ*; }>90 \% \text { tile WAZ*: Pressuring to finish at } 3 \text { mo } \\
\text { was associated with lower WAZ and lower odds of } \\
\text { WAZ }>90^{\text {th }} \% \text { tile at } 3,6,9,12,18 \text { mo of age }\end{array}$ & & $\begin{array}{l}\text { NS: sum SF thickness*; } \\
>90 \% \text { sum SF thickness* }\end{array}$ \\
\hline & Indulgent & NS: WAZ*; >90\% WAZ* & & $\begin{array}{l}\text { NS: sum SF thickness*; } \\
>90 \% \text { sum SF thickness* }\end{array}$ \\
\hline & Laissez-Faire & NS: WAZ*; >90\% WAZ* & & $\begin{array}{l}\text { NS: sum SF thickness*; } \\
>90 \% \text { sum SF thickness* }\end{array}$ \\
\hline \multirow[t]{2}{*}{$\begin{array}{l}\text { Worobey, } \\
2009\end{array}$} & $\begin{array}{l}\text { Responsive } \\
\text { feeding }\end{array}$ & & $\begin{array}{l}\text { WG* 6-12mo: Maternal sensitivity to infant cues at } \\
3 \text { months was associated with less weight gain from } \\
6 \text { to } 12 \mathrm{mo}\end{array}$ & \\
\hline & & & NS: WG* 3-6mo & \\
\hline
\end{tabular}


Study

Design/

\section{Exposure}

\section{Outcomes}

Article

Wright, 2006

$$
\begin{aligned}
& \text { Pressure } \\
& \text { (Maternal } \\
& \text { response to }
\end{aligned}
$$

WG*: Maternal response to food refusal at $8 \mathrm{mo}$

was significantly associated with lower weight gain

food refusal) from birth to $12 \mathrm{mo}$.

* Analysis adjusted for initial body weight or length; ${ }^{+}$Controlled trials weighted less heavily due to study limitations;

BMI: body mass index; BMIZ: body mass index z-score; CWG: conditional weight gain; H: height; HAZ: height-for-age z-score; IWG: insufficient weight gain; L: Length; LG: Length Gain; NS: not significant; Ob: obese; Ow: overweight; RWG: rapid weight gain; SF: Skin Folds; SS: Subscapular; TR: Tricep; W: weight; WAZ: weight for age z-score; WG: weight gain; WHZ: weight for height z-score; WLZ: weight for length z-score; WS: standardized weight. 


\section{Research recommendations}

In order to better assess the relationship between feeding practices and growth, size, and body composition outcomes, additional research is needed.

- Conduct controlled trials to determine the contributions of variation in infant phenotype (e.g., infant feeding and satiation behaviors) and variation in maternal phenotype (e.g., maternal feeding styles) with the type of diet and age of child (e.g., formula, breast milk, complementary foods, table foods) on weight status and rapid weight gain

- Understand the stability of maternal feeding practices over time

- Understand caregiver motivations in the decision-making process related to infant feeding and develop evidence-based guidance that are sensitive to differences in socio-economic status, culture, education, etc.

- Conduct controlled studies to determine the impact of the length of intervention and child age on variation in maternal feeding practices and infant feeding on weight outcomes

- Conduct intervention or longitudinal studies with child care providers of birth to 2-year olds (full-time family or group day care) on child care feeding practices (including responsive feeding) and child weight and growth outcomes

- Conduct research on the association between responsive feeding practices among child care providers of birth to 2-year olds (controlling for parents/home caretakers' practices) and child weight and growth outcomes

- Validate maternal or caregiver reports of infant feeding practices by comparing these measures with objective measures of caregiver feeding practices, infant feeding and satiation (signaling) behaviors

- Randomized controlled trials should include racially and ethnically diverse study populations in the US

\section{Included articles}

1. Brown A, Lee MD. Early influences on child satiety-responsiveness: the role of weaning style. Pediatr Obes. 2015 Feb;10(1):57-66. doi: 10.1111/j.20476310.2013.00207.x. Epub 2013 Dec 17.

2. Chaidez V, McNiven S, Vosti SA, Kaiser LL. Sweetened food purchases and indulgent feeding are associated with increased toddler anthropometry. J Nutr Educ Behav. 2014 Jul-Aug;46(4):293-8.

3. Daniels LA, Mallan KM, Battistutta D, Nicholson JM, Perry R, Magarey A. Evaluation of an intervention to promote protective infant feeding practices to prevent childhood obesity: outcomes of the NOURISH RCT at 14 months of age and 6 months post the first of two intervention modules. Int J Obes (Lond). 2012 Oct;36(10):1292-8. doi: 10.1038/ijo.2012.96. Epub 2012 Jun 19. 
4. Daniels LA, Mallan KM, Nicholson JM, Battistutta D, Magarey A. Outcomes of an early feeding practices intervention to prevent childhood obesity. Pediatrics. 2013 Jul;132(1):e109-18. doi: 10.1542/peds.2012-2882. Epub 2013 Jun 10.

5. Daniels LA, Mallan KM, Nicholson JM, Thorpe K, Nambiar S, Mauch CE, Magarey A. An Early Feeding Practices Intervention for Obesity Prevention. Pediatrics. 2015 Jul;136(1):e40-9. doi: 10.1542/peds.2014-4108. Epub 2015 Jun 8.

6. De Carvalho M, Robertson S, Friedman A, \& Klaus M. Effect of Frequent Breast-Feeding on Early Milk Production and Infant Weight Gain. Pediatrics, 1983;72(3), 307-311.

7. Dinkevich E, Leid L, Pryor K, Wei Y, Huberman H, Carnell S. Mothers' feeding behaviors in infancy: Do they predict child weight trajectories? Obesity (Silver Spring). 2015 Dec;23(12):2470-6. doi: 10.1002/oby.21320. Epub 2015 Nov 5.

8. Farrow $\mathrm{C}$, Blissett J. Does maternal control during feeding moderate early infant weight gain? Pediatrics. 2006 Aug;118(2):e293-8.

9. Farrow CV, Blissett J. Controlling feeding practices: cause or consequence of early child weight? Pediatrics. 2008 Jan;121(1):e164-9. doi:

10.1542/peds.2006-3437.

10. Gregory JE, Paxton SJ, Brozovic AM. Maternal feeding practices predict fruit and vegetable consumption in young children. Results of a 12-month longitudinal study. Appetite. 2011 Aug;57(1):167-72. doi: 10.1016/j.appet.2011.04.012. Epub 2011 Apr 29.

11. Gubbels JS, Thijs C, Stafleu A, van Buuren S, Kremers SP. Association of breast-feeding and feeding on demand with child weight status up to 4 years. Int J Pediatr Obes. 2011 Jun;6(2-2):e515-22. doi: 10.3109/17477166.2010.514343. Epub 2010 Sep 22.

12. Hittner JB, Johnson C, Tripicchio G, Faith MS. Infant emotional distress, maternal restriction at a home meal, and child BMI gain through age 6years in the Colorado Adoption Project. Eat Behav. 2016 Apr;21:135-41. doi: 10.1016/j.eatbeh.2016.01.008. Epub 2016 Jan 28.

13. Kavanagh, KF, Cohen, RJ, Heinig, M. J., \& Dewey, K. G. Educational Intervention to Modify Bottle-feeding Behaviors among Formula-feeding Mothers in the WIC Program: Impact on Infant Formula Intake and Weight Gain. Journal of Nutrition Education and Behavior. 2008;40(4):244-250. doi:10.1016/j.jneb.2007.01.002. 
14. Li, R., Fein, SB, \& Grummer-Strawn, LM Association of breastfeeding intensity and bottle-emptying behaviors at early infancy with infants' risk for excess weight at late infancy. Pediatrics. 2008;122(2):S77-S84.

doi:10.1542/peds.2008-1315j.

15. Lumeng JC, Ozbeki TN, Appugliese DP, Kaciroti N, Corwyn RF, Bradley RH. Observed assertive and intrusive maternal feeding behaviors increase child adiposity. Am J Clin Nutr. 2012 Mar;95(3):640-7. doi: 10.3945/ajcn.111.024851. Epub 2012 Jan 25.

16. Ma JQ, Zhou LL, Hu YQ, Liu SS, Sheng XY. Association between feeding practices and weight status in young children. BMC Pediatr. 2015 Aug 26;15:97. doi: 10.1186/s12887-015-0418-4.

17. Machuca H, Arevalo S, Hackley B, Applebaum J, Mishkin A, Heo M, Shapiro A. Well Baby Group Care: evaluation of a promising intervention for primary obesity prevention in toddlers. Child Obes. 2016 Jun;1293):171-8. doi: 10.1089/chi.2015.0212.

18. Morris SS, Farrier SC, Rodgers CS, \& Taper LJ. Feeding behaviors, food attitudes, and body fatness in infants. Joumal of The American Dietetic Association. 1982 April;80:330-334.

19. Paul IM, Savage JS, Anzman SL, Beiler JS, Marini ME, Stokes JL, Birch LL. Preventing obesity during infancy: a pilot study. Obesity (Silver Spring). 2011 Feb;19(2):353-61. doi: 10.1038/oby.2010.182.

20. Rifas-Shiman SL, Sherry B, Scanlon K, Birch LL, Gillman MW, Taveras EM. Does maternal feeding restriction lead to childhood obesity in a prospective cohort study? Arch Dis Child. 2011 Mar;96(3):265-9. doi: 10.1136/adc.2009.175240. Epub 2010 Nov 16.

21. Savage JS, Birch LL, Marini M, Anzman-Frasca S, Paul IM. Effect of the INSIGHT Responsive Parenting Intervention on Rapid Infant Weight Gain and Overweight Status at Age 1 Year: A Randomized Clinical Trial. JAMA Pediatr. 2016 Aug 1;170(8):742-9. doi: 10.1001/jamapediatrics.2016.0445.

22. Saxon TA, Gollapalli A, Mitchell MW. Demand feeding or schedule feeding: infant growth from birth to 6 months. J Reprod Infant Psychol. 2002;20(2):89-99. 
23. Stifter CA, Moding KJ. Understanding and measuring parent use of food to soothe infant and toddler distress: A longitudinal study from 6 to 18 months of age. Appetite. 2015 Dec;95:188-96. doi: 10.1016/j.appet.2015.07.009.

24. Taveras EM, Rifas-Shiman SL, Scanlon KS, Grummer-Strawn LM, Sherry B, Gillman MW. To what extent is the protective effect of breastfeeding on future overweight explained by decreased maternal feeding restriction? Pediatrics. 2006 Dec;118(6):2341-8.

25. Thompson AL, Adair LS, Bentley ME. Pressuring and restrictive feeding styles influence infant feeding and size among a low-income African-American sample. Obesity (Silver Spring). 2013 Mar;21(3):562-71. doi: 10.1002/oby.20091.

26. Worobey J, Lopez MI, Hoffman DJ. Maternal behavior and infant weight gain in the first year. J Nutr Educ Behav. 2009 May-Jun;41(3):169-75. doi: 10.1016/j.jneb.2008.06.005.

27. Wright CM, Parkinson KN, Drewett RF. How does maternal and child feeding behavior relate to weight gain and failure to thrive? Data from a prospective birth cohort. Pediatrics. 2006 Apr;117(4):1262-9. 


\section{ANALYTIC FRAMEWORK}

The analytic framework (Figure 1) illustrates the overall scope of the systematic review, including the population, the interventions and/or exposures, comparators, and outcomes of interest. It also includes definitions of key terms and identifies key confounders considered in the systematic review. This is the analytic framework for the systematic review conducted to examine the relationship between caregiver feeding practices for children from birth to 24 months old and the weight, growth, and body composition outcomes.

\section{Figure 1: Analytic framework}

Analytic Framework: What is the relationship between parental and caregiver feeding practices (including control, pressure, restriction, monitoring, and responsiveness/non-responsiveness to satiety and hunger cues) and growth, size, and body composition?

\section{SEARCH PLAN AND RESULTS}

\section{Inclusion and exclusion criteria}

The inclusion and exclusion criteria are a set of characteristics to determine which studies will be included or excluded in the systematic review. This table provides the inclusion and exclusion criteria for the systematic review question(s): What is the relationship between caregiver feeding practices for children from birth to 24 months old and the weight, growth, and body composition outcomes? 
Table 3. Inclusion and exclusion criteria

\begin{tabular}{|c|c|c|}
\hline Category & Inclusion Criteria & Exclusion Criteria \\
\hline Study Design & $\begin{array}{l}\text { - Randomized controlled trials } \\
\text { - Non-randomized controlled trials } \\
\text { - Prospective cohort studies } \\
\text { - Retrospective cohort studies } \\
\text { - Pre/post studies with a control } \\
\text { - Nested case control studies }\end{array}$ & $\begin{array}{l}\text { - Case-control studies } \\
\text { - Cross-sectional studies } \\
\text { - Uncontrolled studies } \\
\text { - Pre/post studies without a control } \\
\text { - Narrative reviews } \\
\text { - Systematic reviews } \\
\text { - Meta-analyses }\end{array}$ \\
\hline $\begin{array}{l}\text { Publication } \\
\text { Status }\end{array}$ & $\begin{array}{l}\text { - Studies published in peer-reviewed } \\
\text { journals }\end{array}$ & $\begin{array}{l}\text { - Grey literature, including } \\
\text { unpublished data, manuscripts, } \\
\text { reports, abstracts, conference } \\
\text { proceedings }\end{array}$ \\
\hline Language & - Studies published in English & $\begin{array}{l}\text { - Studies published in languages } \\
\text { other than English }\end{array}$ \\
\hline Date Range & - Studies published from 1980-present ${ }^{i v}$ & - Studies published prior to 1980 \\
\hline $\begin{array}{l}\text { Intervention/ } \\
\text { Exposure }\end{array}$ & $\begin{array}{l}\text { Measured parental or caregiver feeding } \\
\text { practice/s assessed using objective (e.g., } \\
\text { meal observations) or subjective (i.e., } \\
\text { self-report questionnaire) methods. }\end{array}$ & - N/A \\
\hline Comparator & $\begin{array}{l}\text { Differing degrees of control, pressure, } \\
\text { restriction and responsive/non- } \\
\text { responsive/pressuring/indulgent feeding } \\
\text { practice; differing feeding practices }\end{array}$ & - $\quad \mathrm{N} / \mathrm{A}$ \\
\hline
\end{tabular}

iv Consistent across the Pregnancy and Birth to 24 months Project 


\section{Exclusion Criteria}

\section{- N/A}

\begin{tabular}{|c|c|}
\hline Category & Inclusion Criteria \\
\hline Growth, Size & Intermediate Outcomes \\
\hline and Body & - Weight and height \\
\hline Composition & - BMI, BMI z-score \\
\hline \multirow[t]{8}{*}{ Outcomes } & - Waist circumference \\
\hline & - Weight change \\
\hline & - Weight status change \\
\hline & - Child indices: \\
\hline & $\begin{array}{l}\text { o Size: Weight-for-age, length/stature-for- } \\
\text { age, weight-for-length, head, arm, and } \\
\text { thigh circumference for age }\end{array}$ \\
\hline & $\begin{array}{l}\text { o Growth: Change across more than one } \\
\text { time point of weight-for age, length-for- } \\
\text { age, weight-for-length, head, arm, and } \\
\text { thigh circumference for age }\end{array}$ \\
\hline & $\begin{array}{l}\text { - Body composition: \% fat mass, } \% \text { fat free } \\
\text { mass, bone mineral density }\end{array}$ \\
\hline & - Skin-folds \\
\hline
\end{tabular}

Growth, Size

and Body

Composition

Skin-folds

Health Outcomes

- Incidence and prevalence of healthy weight, overweight, obesity

o Children: BMI-for-age percentile or zscore

- Incidence and prevalence of underweight or failure to thrive, stunting, and wasting in infants and children

\begin{tabular}{lll}
\hline $\begin{array}{l}\text { Study } \\
\text { Setting/Country }\end{array}$ & $\begin{array}{l}\text { Studies conducted in Very High or High } \\
\text { Human Development Countries }\end{array}$ & $\begin{array}{l}\text { Studies conducted in Medium or } \\
\text { Low Human Development } \\
\text { Countriesv }\end{array}$ \\
\hline Study Subjects & $\bullet$ Human subjects & $\begin{array}{l}\text { Hospitalized patients, not including } \\
\text { birth and immediate post-partum } \\
\text { hospitalization of healthy mothers } \\
\text { and babies }\end{array}$ \\
\hline $\begin{array}{l}\text { Size of Study } \\
\text { Groups }\end{array}$ & - N/A & $\bullet$ \\
\hline
\end{tabular}

${ }^{\vee}$ Determined using the 2014 Human Development Index 


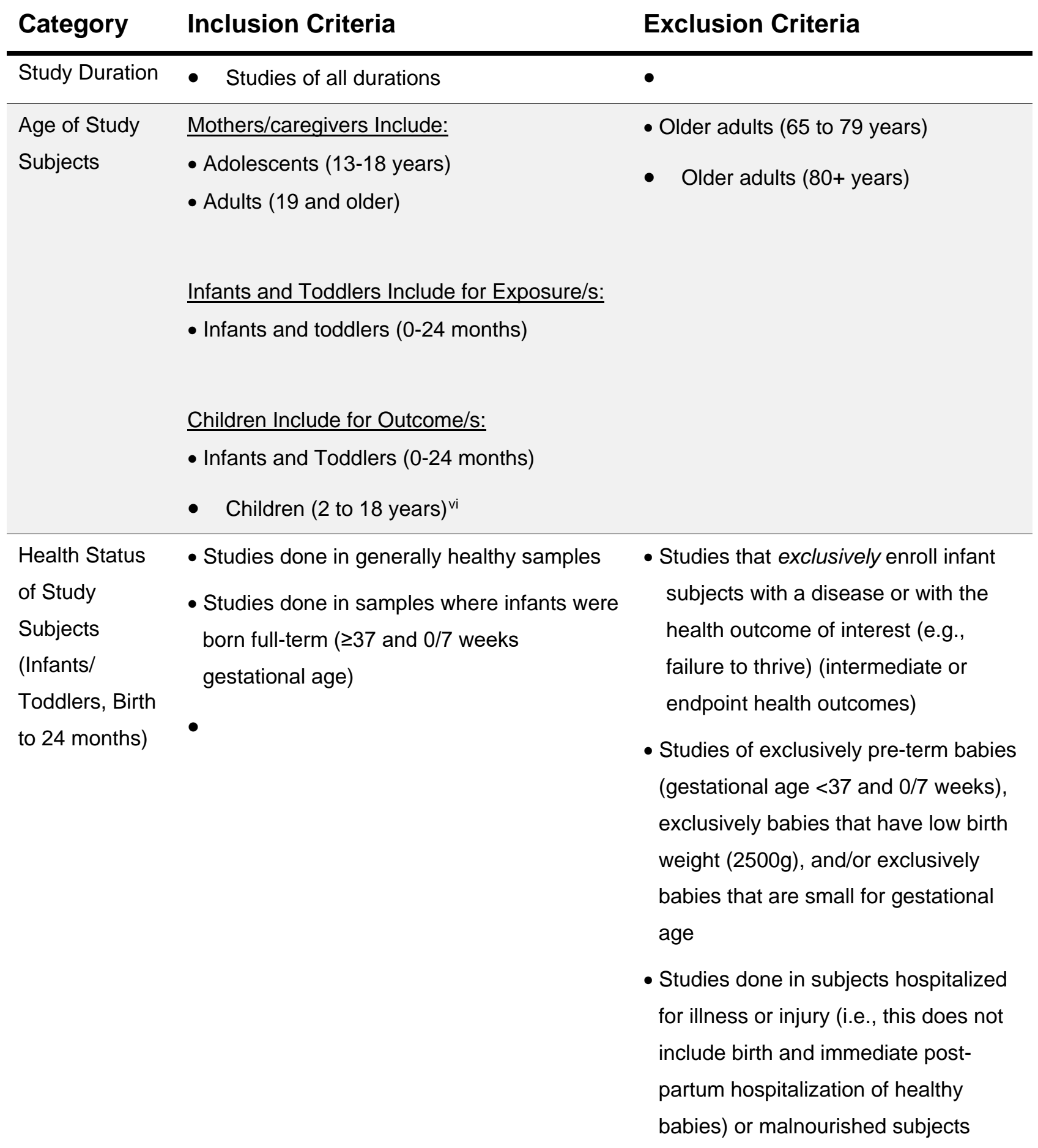

\footnotetext{
vi Include studies that had an age range going beyond 24 months if there was subgroup analysis specifically for ages $<=24$ mo
} 


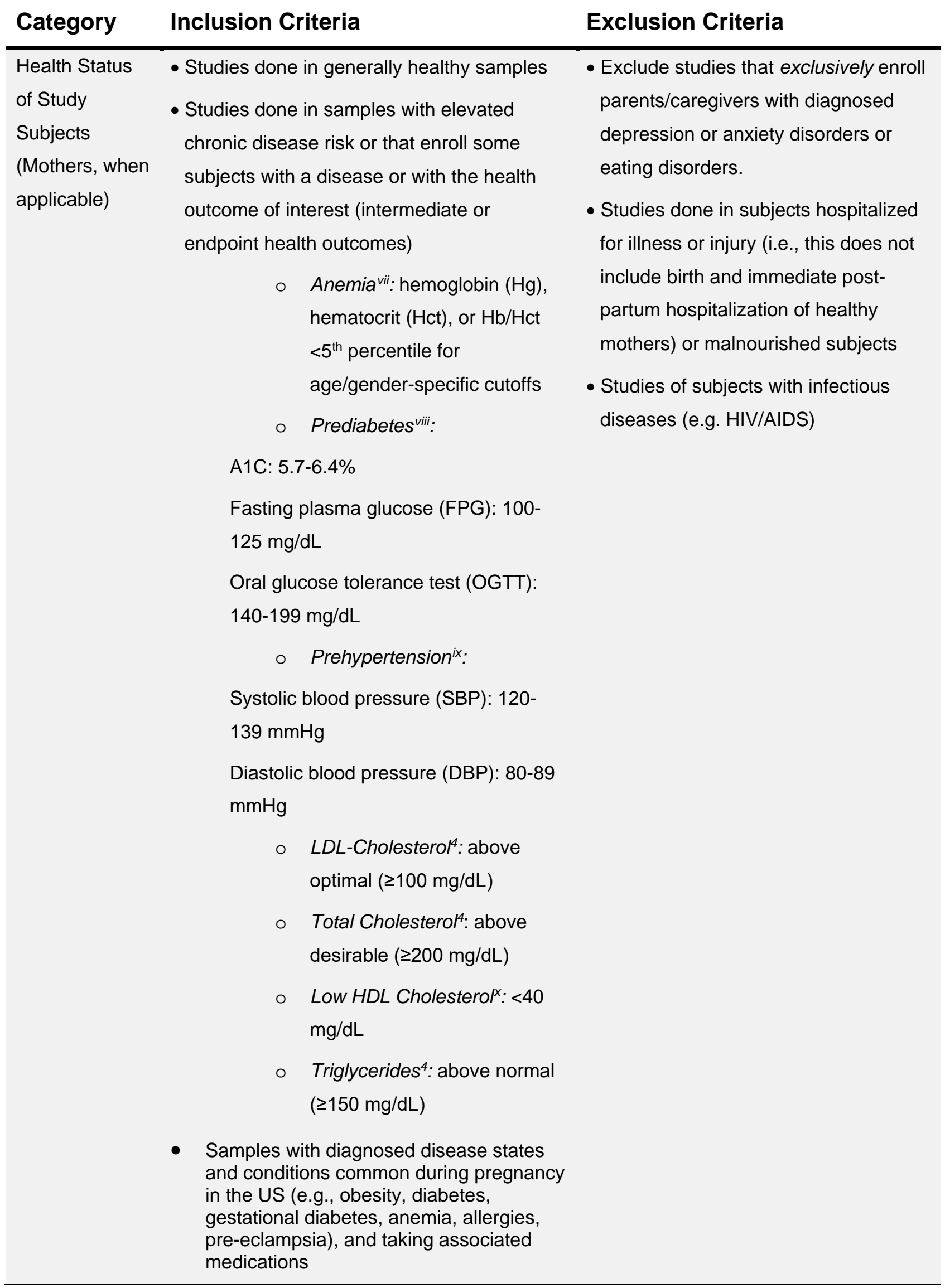




\begin{tabular}{|c|c|c|}
\hline Category & Inclusion Criteria & Exclusion Criteria \\
\hline Risk of Bias & $\begin{array}{l}\text { - All studies regardless of NEL BAT risk of } \\
\text { bias rating }\end{array}$ & - N/A \\
\hline Study Design & $\begin{array}{l}\text { - Randomized controlled trials } \\
\text { - Non-randomized controlled trials } \\
\text { - Prospective cohort studies } \\
\text { - Retrospective cohort studies } \\
\text { - Pre/post studies with a control } \\
\text { - Nested case control studies }\end{array}$ & $\begin{array}{l}\text { - Case-control studies } \\
\text { - Cross-sectional studies } \\
\text { - Uncontrolled studies } \\
\text { - Pre/post studies without a control } \\
\text { - Narrative reviews } \\
\text { - Systematic reviews } \\
\text { - Meta-analyses }\end{array}$ \\
\hline $\begin{array}{l}\text { Publication } \\
\text { Status }\end{array}$ & $\begin{array}{l}\text { - Studies published in peer-reviewed } \\
\text { journals }\end{array}$ & $\begin{array}{l}\text { - Grey literature, including } \\
\text { unpublished data, manuscripts, } \\
\text { reports, abstracts, conference } \\
\text { proceedings }\end{array}$ \\
\hline
\end{tabular}

\section{Search terms and electronic databases used}

\section{Pubmed}

- $\quad$ Date(s) Searched: $1 / 5 / 17$

- Search date range: $1980-1 / 5 / 2017$

- Search Terms:

(incentiv* OR indulgen*[tiab] OR authorita*[tiab] OR reward* OR control* OR pressur* OR

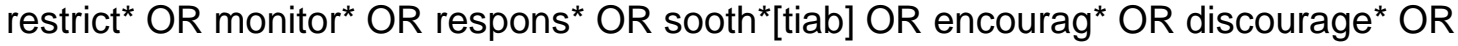
uninvolv* OR disengage* OR parenting style* OR laissez-faire OR laissez faire* OR nonrespons* OR nonrespons* OR force*

AND

feeding* OR fed[tiab] OR eat[tiab] OR eating OR bottle feed* OR bottlefeed* OR "Bottle feeding"[mh] OR bottle feed*[ti] OR bottle-feed*[tiab] OR bottle-fed[tiab] OR "bottle fed"[tiab])

OR

("Feeding Methods"[Mesh:noexp] OR "Feeding Behavior"[Mesh:NoExp] OR ((satiety OR hunger OR hungry OR satiat*) AND (cue OR cues)) OR feeding method* OR feeding practice* OR feeding pattern* OR feeding frequenc* OR infant feed* OR feeding behavior*[tiab] OR feeding style* OR feeding strategy*)

AND

Growth[mh:noexp] OR "Child Development"[Mesh] OR "Growth Charts"[Mesh] OR "growth and development" [Subheading] OR "Growth and

\footnotetext{
vii CDC, 1998

viii NIDDK, 2014

ix NHLBI, 2004

${ }^{x}$ NHLBI, 2001
} 
Development"[Mesh:noexp] OR "Growth"[tiab] OR "Child Development"[Mesh] OR child develop*[tiab] OR "Overnutrition"[Mesh] OR overeat* OR overfed OR overfeed* OR under-nutrition[tiab] OR undernutrition[tiab] OR stunting*[tiab] OR stunted[tiab] OR "developmental delay"[tiab] OR "Bone Density"[Mesh] OR "bone density"[tiab] OR "Bone Development"[Mesh] OR "Bone Development"[tiab] OR "Growth Disorders"[Mesh] OR "body size"[tiab] OR body size[mh] OR obesity[tiab] OR obese[tiab] OR overweight[mh] OR obesity[mh] OR overweight [tiab] OR adipos*[tiab] OR adiposity[mh] OR body composition[mh] OR body fat distribution[mh] OR "body fat"[tiab] OR "body weight"[tiab] OR body weight[mh] OR birth weight*[tiab] OR weight gain[mh] OR weight loss[mh] OR "body-weight"[tiab] OR "weight gain"[tiab] OR weight-gain[tiab] OR weight loss[tiab] OR weightloss[tiab] OR Body Weights and Measures[mh] OR weight[ti] OR "Anthropometry"[Mesh:noexp] OR body mass index[mh] OR "body mass index"[tiab] OR BMI[tiab] OR "weight status"[tiab] OR adipose tissue [mh] OR "healthy weight"[tiab] OR waist circumference[mh] OR "body mass"[ti] OR "fat mass"[tiab] OR body weight changes[mh] OR "waist circumference"[tiab] OR ideal body weight[mh] OR waist-hip ratio[mh] OR Waist Hip*[tiab] OR body height*[tiab] OR Crown-Rump Length*[tiab] OR head circumference*[tiab] OR arm circumference*[tiab] OR thigh circumference* OR limb circumference* OR fat free mass*[tiab] OR skinfold[tiab] OR skin fold*[tiab]

\begin{abstract}
AND
infant* OR baby OR babies OR toddler* OR newborn*[tiab] OR "Child, Preschool"[Mesh]

OR preschool*[tiab] OR pre-school*[tiab] OR "early childhood"[tiab] OR early year*[tiab] OR pre-k[tiab] OR pre-primary[tiab] OR under five*[ti] OR young child*[ti] OR

prekindergarten[tiab] OR pre-kindergarten[tiab] OR weanling* OR "first two years" OR "first 2 years"

NOT (editorial[ptyp] OR comment[ptyp] OR news[ptyp] OR letter[ptyp] OR review[ptyp] OR systematic[sb])
\end{abstract}

\title{
Embase
}

- $\quad$ Date(s) Searched: $1 / 3 / 17$

- Search Terms:

1.

(incentive* OR indulgen* OR authorita* OR reward* OR control* OR pressur* OR restrict* OR monitor* OR respons* OR sooth* OR encourag* OR discourage* OR uninvolv* OR disengage*) OR nonrespons* OR non-respons* OR force*

\section{2. (parent* NEAR/3 style*)}

(1 OR 2) AND (beverage/exp OR feeding/de OR drinking/de OR eating/de OR diet/de OR meal/de OR 'baby food'/exp

\section{$1 \mathrm{NEAR} / 3$}

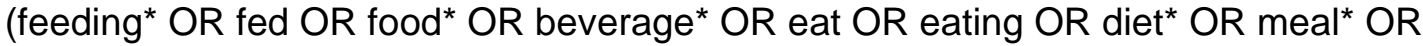
bottlefeed* OR bottlefed OR "bottle fed" OR "bottle feeding" OR "bottle feed" OR "laissez faire")) 
(Feed* NEAR/3 (response* OR method* OR practice* OR pattern* OR frequenc* OR style* OR strateg*)) OR

((satiety OR hunger OR hungry OR satiat*) NEAR/3 (cue OR cues))

AND

infant*:ti,ab OR infant/exp OR (baby OR babies OR toddler* OR newborn* OR

nurser*):ti,ab OR 'newborn'/exp OR 'newborn care'/exp OR preschool*:ti,ab OR pre-

school:ti,ab OR 'preschool child'/exp OR 'infancy'/exp OR "early childhood":ti,ab OR "early years":ti,ab OR pre-k:ti,ab OR 'nursery'/exp OR 'nursery school'/exp OR

prekindergarten:ti,ab OR pre-kindergarten:ti,ab OR weanling*:ti,ab

AND ([in process]/lim OR [article]/lim OR [article in press]/lim) AND ([embase]/lim NOT [medline]/lim)

AND

'clinical article'/exp OR 'clinical trial':tiab OR 'controlled study':ti,ab OR 'clinical study':ti,ab OR 'randomized controlled':ti,ab OR 'clinical study':ti,ab OR 'cohort analysis'/exp OR cohort: ti,ab OR 'types of study'/exp Don't use?

Limit to Eng/humans:

AND

'postnatal development'/exp OR 'postnatal development':ti,ab OR 'overnutrition'/exp OR 'overnutrition':ti,ab OR undernutrition:ti,ab OR "developmental delay":ti,ab OR 'stunting'/exp OR stunting:ti,ab OR

(bone NEAR/2 (health* OR density OR mineralize* OR demineraliz*)):ti,ab OR 'bone density'/exp

OR

'body size'/de OR 'body size':ti,ab OR 'obesity'/exp OR overweight:ab,ti OR

'macrosomia'/exp OR obese:ab,ti OR obesity:ab,ti OR 'weight gain':ab,ti OR adiposity:ab,ti

OR adipose:ab,ti OR 'body weight'/exp OR 'body weight':ti,ab OR 'weight gain'/de OR 'body composition'/exp OR 'body composition':ti,ab OR 'body fat':ab,ti OR 'anthropometry'/de OR 'body mass'/de OR bmi:ab,ti OR 'body mass':ab,ti OR weight:ab,ti OR (waist NEXT/1 hip NEXT/1 ratio*) OR 'body fat'/de OR 'adipose tissue'/exp OR skinfold OR 'skin fold':ti,ab OR 'fat mass':ti,ab OR 'fat mass'/exp OR 'anthropometric parameters'/exp OR circumference OR length OR height

OR

'body growth'/exp 'body growth':ti,ab OR 'growth rate and growth regulation'/exp OR 'postnatal growth'/exp OR 'human development'/exp OR 'Bayley Scales of Infant Development'/exp

OR ([newborn]/lim OR [infant]/lim OR [child]/lim OR [preschool]/lim)

AND ([in process]/lim OR [article]/lim OR [article in press]/lim) AND ([embase]/lim NOT [medline]/lim)

\section{Cochrane}

- Date(s) Searched: $1 / 3 / 17$ 
- Search Terms:

incentive* OR indulgen* OR authorita* OR reward* OR control* OR pressur* OR restrict* OR monitor* OR respons* OR sooth* OR encourag* OR discourage* OR uninvolv* OR disengage* OR "laissez faire" OR (parenting NEAR/3 style*) OR nonrespons* OR nonrespons* OR force*

NEAR/3

(feeding* OR fed OR food* OR beverage* OR eat OR eating OR diet* OR meal* meals OR meal OR bottlefeed* OR bottlefed OR "bottle fed" OR "bottle feeding")

[mh ^food] ORf [mh "infant food"]

[mh "Feeding Methods"] OR [mh ^ "Feeding Behavior"] OR (Feed* NEAR/3 (respons* OR

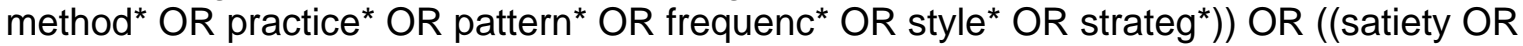
hunger OR hungry OR satiat*) NEAR/3 (cue OR cues))

OR

[mh "infant food"]

OR

infant*:ti,ab OR (baby OR babies OR toddler* OR newborn* OR nurser*):ti,ab OR 'newborn' OR preschool*:ti,ab OR pre-school:ti,ab OR "early childhood":ti,ab OR "early years" OR pre-k:ti,ab OR 'nursery' OR prekindergarten:ti,ab OR pre-kindergarten:ti,ab OR weanling*

infant* OR baby OR babies OR toddler* OR newborn* OR nurser* OR preschool* OR preschool OR "early childhood" OR "early years" OR pre-k OR prekindergarten OR prekindergarten OR weanling*

AND

[mh ^Growth] OR [mh "Child Development"] OR [mh "Growth Charts"] OR "growth and development" OR [mh^"Growth and Development"] OR [mh "Child Development"] OR (child NEAR/1 develop*):ti,ab OR [mh "Overnutrition"] OR under-nutrition:ti,ab OR undernutrition:ti,ab

OR 'body growth':ti,ab OR 'growth rate and growth regulation' OR 'postnatal growth':ti,ab OR 'human development':ti,ab OR 'Bayley Scales of Infant Development' OR Stunt*:ti,ab OR wasting:ti,ab OR 'postnatal development':ti,ab OR 'overnutrition':ti,ab OR "developmental delay":ti,ab OR [mh "Bone Density"] OR [mh "Bone Development"] OR (bone NEAR/2 (health* OR density OR mineral* OR demineral* OR develop* OR mass)):ti,ab OR 'body size':ti,ab OR overweight:ab,ti OR 'macrosomia':ti,ab OR obese:ab,ti OR obesity:ab,ti OR adipos*:ab,ti OR 'body weight':ti,ab OR 'weight gain':ti,ab OR 'body composition':ti,ab OR 'body fat':ab,ti OR 'anthropometr':ti,ab OR bmi:ab,ti OR 'body mass':ab,ti OR (waist NEXT/1 hip NEXT/1 ratio*) OR 'body fat':ti,ab OR 'adipose tissue':ti,ab OR skinfold:ti,ab OR 'skin fold':ti,ab OR 'fat mass':ti,ab OR circumference:ti,ab OR length:ti,ab OR height:ti,ab OR [mh "body size"] OR [mh overweight] OR [mh obesity] OR [mh adiposity] OR [mh "body composition"] OR [mh "body fat distribution"] OR [mh "body weight"] OR [mh "weight gain"] OR [mh "weight loss"] OR "weight loss":ti,ab OR [mh "Body Weights and Measures"] OR weight:ti OR [mh ^"Anthropometry"] OR [mh "body mass index"] OR "weight status":ti,ab OR [mh "adipose tissue"] OR "healthy weight":ti,ab OR [mh "waist circumference"] OR [mh "body weight changes"] OR [mh "ideal body weight"] OR [mh "waist-hip ratio"] OR "waist-hip":ti,ab OR "Crown-Rump":ti,ab OR "fat free mass":ti,ab 


\section{CINAHL (Plus)}

- Date(s) Searched: 1/5/17

- Search Terms:

1.

(incentive* OR indulgen* OR authorita* OR reward* OR control* OR pressur* OR restrict* OR monitor* OR respons* OR sooth* OR encourag* OR discourage* OR uninvolv* OR disengage* OR (parenting n3 style*) OR "laissez faire" OR nonrespons* OR non-respons* OR force ${ }^{\star}$ )

n3

(feeding* OR fed OR food* OR beverage* OR eat OR eating OR diet* OR meal* OR meals OR meal OR bottlefeed* OR bottlefed OR "bottle fed" OR "bottle feeding")

\section{AND}

(MH "Food and Beverages") OR (MH "Food") OR (MH "Diet") OR (MH "Eating") OR (MH "Eating Behavior") OR (MH "Meals+")

(Feed* n3 (respons* OR nonresponse* OR non-respons* OR method* OR practice* OR pattern* OR frequenc* OR style* OR strateg*)) OR ((satiety OR hunger OR hungry OR satiat $\left.^{\star}\right)$ n3 (cue OR cues)) OR (MH "Infant Feeding+")

AND

(MH "Anthropometry+") OR (MH "Body Weights and Measures+") OR (MH "Body Weight+") OR

(MH "Bone Development+") OR (MH "Growth+") OR (MH "Human Development+") OR "bayley scales" OR "mental function" OR (MH "Body Size") OR (MH "Obesity+") OR "overweight" OR "macrosomia" OR (MH "Weight Gain+") OR (MH "Waist-Hip Ratio") OR (MH "Body Composition+") OR (MH "Adipose Tissue+") OR (MH "Abdominal Fat") OR (MH "Fat Free Mass") OR (MH "Body Mass Index") OR (MH "Skinfold Thickness") OR (MH "Head Circumference") OR (MH "Arm Circumference") OR (MH "Waist Circumference") OR (MH "Growth and Development (Omaha)") OR (MH "Body Height") OR (MH "Crown-Rump Length") OR (MH "Leg Length Inequality") OR (bone n2 (develop* OR health* OR density OR mineralize* OR demineraliz*) OR (MH "Bone Density") OR (MH "Growth and Development (Iowa NOC)+") OR (MH "Growth and Embryonic Development+") OR (MH "Infant Development")

Limit to "all infant" OR

(MH "Infant") OR (MH "Infant, Newborn") OR (MH "Infant Behavior") OR (MH "Infant Feeding") OR (MH "Infant Feeding Schedules") OR (MH "Child, Preschool") OR infant* OR baby OR babies OR toddler* OR newborn* OR nurser* OR preschool* OR pre-school OR "early childhood" OR "early years" OR pre-k OR prekindergarten OR pre-kindergarten OR weanling*

Limiters - Published Date: 19800101-; English Language; Exclude MEDLINE records

Narrow by Journal: - ambulatory child health

Narrow by Journal: - british journal of midwifery 
Narrow by Journal: - canadian journal of dietetic practice \& research

Narrow by Journal: - communicating nursing research

Narrow by Journal: - contemporary ob/gyn

Narrow by Journal: - infant

Narrow by Journal: - international journal of childbirth education

Narrow by Journal: - jognn: journal of obstetric, gynecologic \& neonatal nursing

Narrow by Journal: - journal for nurse practitioners

Narrow by Journal: - journal of family health care

Narrow by Journal: - journal of neonatal nursing

Narrow by Journal: - journal of the royal society for the promotion of health

Narrow by Journal: - malaysian journal of nutrition

Narrow by Journal: - nursing for women's health

Narrow by Journal: - nursing in practice: the journal for today's primary care nurse

Narrow by Journal: - nutrition \& dietetics

Narrow by Journal: - nutrition bulletin

Narrow by Journal: - nutrition today

Narrow by Journal: - practice nurse

Narrow by Journal: - professional care of mother \& child

Narrow by Journal: - topics in clinical nutrition

Narrow by Journal: - zero to three

Narrow by SubjectAge: - all infant

Figure 2: Flow chart of literature search and screening results

Figure 2. Literature selection flow chart

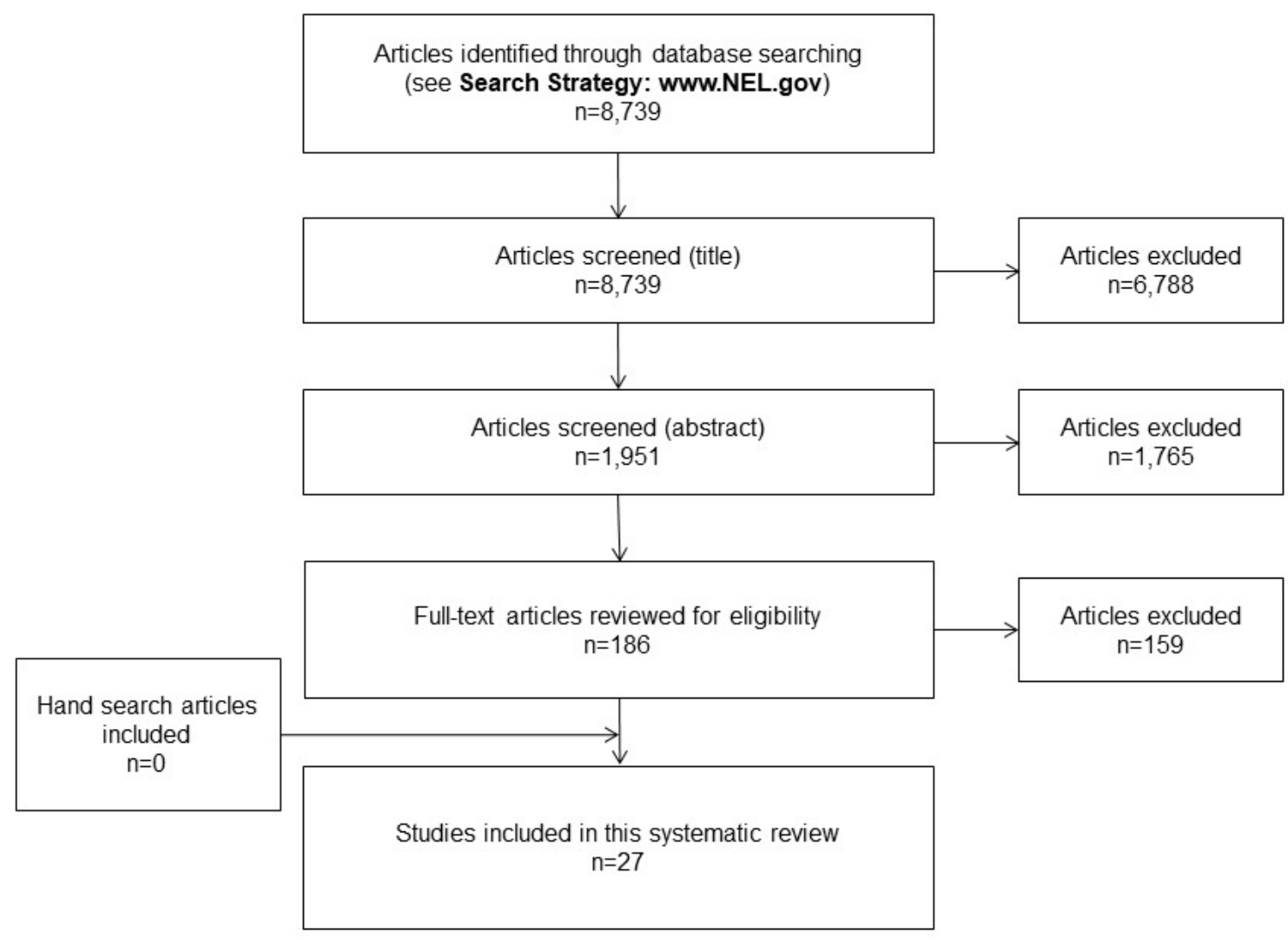

This flow chart illustrates the literature search and screening results for articles examining the relationship between caregiver feeding practices for children from birth 
to 24 months old and the weight, growth, and body composition outcomes. The results of the electronic database searches were screened independently by two NESR analysts in a step-wise manner by reviewing titles, abstracts, and full text articles to determine which articles met the criteria for inclusion. A manual search was done to ascertain articles not identified through the electronic database search. The systematic review on included 27 articles. 


\section{Excluded articles}

The table below lists the excluded articles with at least one reason for exclusion, and may not reflect all possible reasons.

Table 4. Excluded articles

\section{Citation}

Aboud, FE, Shafique, S, Akhter, S. A responsive feeding intervention increases children's self-feeding and maternal responsiveness but not weight gain. J Nutr, 2009, 139: 1738-43. PMID:19587124.

Agras, WS, Hammer, LD, McNicholas, F et al. Risk factors for childhood overweight: a prospective study from birth to 9.5 years. J Pediatr, 2004, 145: 20-5. PMID:15238901.
Reasons for Exclusion

\section{Country}
Alexander, MA, Blank, JJ. Factors related to obesity in
Age
Mexican-American preschool children. Image J Nurs Sch, 1988, 20: 79-82. PMID:3378822.
Ali, N,Zahra, T,Vosogh, MN,Vosoghi, N,Zare, M,Mardi, Independent variable A,Davoud, A, Yousef, HA, Rafat, K. Effectiveness Comparison of Mothers' In-person Versus Written Nutritional Education Intervention on Infant Growth in Iran. Int J MCH AIDS. 2015;3:74. PMID:27621988.
Al-Othman, AM, Reilly, JJ, Belton, NR. Comparative study between young children of different societies to evaluate the impact of feeding style on the nutritional status. Journal of Medical Sciences, 2006, 6: 12-17 Age

American Academy of Pediatrics: Committee on Nutrition. Study design On the feeding of supplemental foods to infants. Pediatrics. 1980;65:1178. PMID:7375248.

Anderson, CB, Hughes, SO, Fisher, JO et al. Cross-cultural Age equivalence of feeding beliefs and practices: the psychometric properties of the child feeding questionnaire among Blacks and Hispanics. Prev Med, 2005, 41: 521-31. PMID:15917048.

Barroso C.S., A. Roncancio, M. W. Moramarco, M. B. Study design Hinojosa, Y. R. Davila, E. Mendias, E. Reifsnider. Food security, maternal feeding practices and child weight-forlength. Appl Nurs Res. 2016;29:31-6. PMID:26856485. Baughcum, AE, Powers, SW, Johnson, SB et al. Maternal Study design feeding practices and beliefs and their relationships to overweight in early childhood. J Dev Behav Pediatr, 2001, 22: 391-408. PMID:11773804. 
Bergmeier, H, Skouteris, H, Horwood, S et al. Child

temperament and maternal predictors of preschool

children's eating and body mass index. A prospective study.

Appetite, 2014, 74: 125-32. PMID:24345325.

Bergmeier, HJ, Skouteris, H, Haycraft, E et al. Reported

Age

and observed controlling feeding practices predict child

eating behavior after 12 months. J Nutr, 2015, 145: 1311-6.

PMID:25878204.

Bhandari, N, Mazumder, S, Bahl, R et al. An educational

Independent variable

intervention to promote appropriate complementary feeding

practices and physical growth in infants and young children

in rural Haryana, India. J Nutr, 2004, 134: 2342-8.

PMID:15333726.

Bhandari, N,Bahl, R,Nayyar, B,Khokhar, P,Rohde, JE,Bhan, Country

MK. Food supplementation with encouragement to feed it to

infants from 4 to 12 months of age has a small impact on

weight gain. J Nutr. 2001;131:1946. PMID:11435512.

Bindon, JR,Cabrera, C. Infant feeding patterns and growth Independent variable of infants in American Samoa during the first year of life.

Hum Biol. 1988;60:81. PMID:3371960.

Birch, LL, Fisher, JO, Grimm-Thomas, K et al. Confirmatory Age

factor analysis of the Child Feeding Questionnaire: a

measure of parental attitudes, beliefs and practices about

child feeding and obesity proneness. Appetite, 2001, 36:

201-10. PMID:11358344.

Black, MM,Siegel, EH,Abel, Y,Bentley, ME. Home and Independent variable, videotape intervention delays early complementary feeding among adolescent mothers. Pediatrics. 2001;107.

PMID:11331717.

Blissett, J, Haycraft, E. Are parenting style and controlling Age feeding practices related?. Appetite, 2008, 50: 477-85.

PMID:18023502.

Bohn, CM,Haskins, DD,Loo, RK,Ahrendt, LJ. Evaluation of Dependent variable the South Dakota fitCare child care provider training program targeting nutrition and physical activity. S D Med. 2014;67:305. PMID:25163224.

Braet, C, Van,. Curbing obesity: prevention and treatment. Study design Eur J Public Health, 2005, 15: 561-3. PMID:16338985.

Briley, M,McAllaster, M. Nutrition and the child-care setting. Study design J Am Diet Assoc. 2011;111:1298. PMID:21872691.

Brodish, MS. Relationship of early bonding to initial infant Independent variable feeding patterns in bottle-fed newborns. JOGN Nurs.

1982;11:248. PMID:6922277. 
Brown, A, Lee, M. Breastfeeding is associated with a

maternal feeding style low in control from birth. PLoS One, 2013, 8. PMID:23382881.

Brown, A, Lee, M. Maternal child-feeding style during the weaning period: association with infant weight and maternal eating style. Eat Behav, 2011, 12: 108-11. PMID:21385639.

Building on the success of Change 4 Life. Pract Midwife. 2010;13:32. PMID:20162888.

Burdette, HL, Whitaker, RC, Hall, WC et al. Maternal infantfeeding style and children's adiposity at 5 years of age. Arch Pediatr Adolesc Med, 2006, 160: 513-20. PMID:16651495.

Cameron, AJ, Ball, K, Hesketh, KD et al. Variation in outcomes of the Melbourne Infant, Feeding, Activity and Nutrition Trial (InFANT) Program according to maternal education and age. Prev Med, 2014, 58: 58-63.

PMID:24201090.

Campbell, KJ, Lioret, S, McNaughton, SA et al. A parentfocused intervention to reduce infant obesity risk behaviors:

a randomized trial. Pediatrics, 2013, 131: 652-60.

PMID:23460688.

Cannon, G. Out of the box. Public Health Nutr. 2005;8:113. PMID:15877904.

Cao, YT,Svensson, V,Marcus, C,Zhang, J,Zhang, JD, Sobko, T. Eating behaviour patterns in Chinese children aged 12-18 months and association with relative weight-factorial validation of the Children's Eating Behaviour Questionnaire. Int J Behav Nutr Phys Act. 2012;9:5.

PMID:22272572.

Cartagena D., S. W. Ameringer, J. M. McGrath, S. W. Masho, N. Jallo, B. J. Myers. Factors contributing to infant overfeeding in low-income immigrant Latina mothers. Appl Nurs Res. 2015;28:316-21. PMID:26608432.

Chavez, A,Martinez, C,Schlaepfer, L. Health effects of supplementary feeding programs. Prog Clin Biol Res. 1981;67:129. PMID:7301849.

Chiasson, MA,Scheinmann, R,Hartel, D,McLeod, N,Sekhobo, J,Edmunds, LS,Findley, S. Predictors of Obesity in a Cohort of Children Enrolled in WIC as Infants and Retained to 3 Years of Age. J Community Health. 2016;41:127. PMID:26280211.

Corsini, N, Wilson, C, Kettler, L et al. Development and preliminary validation of the Toddler Snack Food Feeding Questionnaire. Appetite, 2010, 54: 570-8. PMID:20211670.
Study design

Study design, Independent variable

\section{Age}

Independent variable
Study design

Study design,

Independent variable
Dependent variable

Independent variable 
Cross, MB, Hallett, AM, Ledoux, TA et al. Effects of

children's self-regulation of eating on parental feeding practices and child weight. Appetite, 2014, 81: 76-83.

PMID:24930598.

Daniels, LA, Mallan, KM, Battistutta, D et al. Child eating behavior outcomes of an early feeding intervention to reduce risk indicators for child obesity: the NOURISH RCT.

Obesity (Silver Spring), 2014, 22. PMID:24415390.

de,, Vrijkotte, TG,Fall, CH,van,,Osmond, C,Gemke, RJ. Correction: Associations of Infant Feeding and Timing of Weight Gain and Linear Growth during Early Life with Childhood Blood Pressure: Findings from a Prospective Population Based Cohort Study. PLoS One. 2016;11. PMID:27992607.

Doring, N,Ghaderi, A,Bohman, B,Heitmann, BL,Larsson, C,Berglind, D,Hansson, L,Sundblom, E,Magnusson, M,Blennow, M,Tynelius, P,Forsberg, L,Rasmussen, F. Motivational Interviewing to Prevent Childhood Obesity: A Cluster RCT. Pediatrics. 2016;137. PMID:27244793.

Ek A. , K. Sorjonen, J. Nyman, C. Marcus, P. Nowicka. Child behaviors associated with childhood obesity and parents' self-efficacy to handle them: confirmatory factor analysis of the Lifestyle Behavior Checklist. Int J Behav Nutr Phys Act. 2015;12:36. PMID:25889819.

Emmett, PM,Jones, LR. Diet and growth in infancy: relationship to socioeconomic background and to health and development in the Avon Longitudinal Study of Parents and Children. Nutr Rev. 2014;72:483. PMID:24947274.

Farrow, C, Blissett, J, Haycraft, E. Does child weight influence how mothers report their feeding practices?. Int J Pediatr Obes, 2011, 6: 306-13. PMID:21728778.

Fawcett, JN. Feeding from birth to 18 months. Nursing (Lond), 1981, : 956-8. PMID:6906622.

Fildes, A, van,, Llewellyn, C et al. Parental control over feeding in infancy. Influence of infant weight, appetite and feeding method. Appetite, 2015, 91: 101-6.

PMID:25862983.

Frankel, LA, O'Connor, TM, Chen, TA et al. Parents' perceptions of preschool children's ability to regulate eating. Feeding style differences. Appetite, 2014, 76: 166-74. PMID:24533968.

Fuemmeler, BF,Stroo, M,Lee, CT,Bazemore, S,Blocker, B,Ostbye, T. Racial Differences in Obesity-Related Risk Factors Between 2-Year-Old Children Born of Overweight Mothers. J Pediatr Psychol. 2015;40:649. PMID:25797946.
Dependent variable

Study design,

Independent variable
Independent variable
Age

Study design,

Independent variable

\section{Age}

Study design

Dependent variable, Study design

Age

Study design, Dependent variable 
Galler, JR, Ramsey, FC, Harrison, RH et al. Infant feeding Independent variable practices in Barbados predict later growth. J Nutr, 1998, 128: 1328-35. PMID:9687552.

Galloway, AT,Fiorito, LM,Francis, LA,Birch, LL. 'Finish your Age soup': counterproductive effects of pressuring children to eat on intake and affect. Appetite. 2006;46:318.

PMID:16626838.

Galson, SK. Childhood overweight and obesity prevention. Not peer reviewed Public Health Rep, 2008, 123: 258-9. PMID:19006963.

Gan, CY,Chin, B,Teoh, ST,Chan, MK. Nutritional status of Independent variable Kadazan children in a rural district in Sabah, Malaysia.

Southeast Asian J Trop Med Public Health. 1993;24:293.

PMID:8266232.

Gibbs, BG, Forste, R. Socioeconomic status, infant feeding Independent variable practices and early childhood obesity. Pediatr Obes, 2014,

9: 135-46. PMID:23554385.

Gibson, P. Childhood obesity: an approach to weight management. J Fam Health Care, 2002, 12: 88-9.

PMID:12416013.

Gross, RS, Briggs, RD, Hershberg, RS et al. Early Child Age

Social-Emotional Problems and Child Obesity: Exploring the Protective Role of a Primary Care-Based General Parenting Intervention. J Dev Behav Pediatr, 2015, 36: 594-604.

PMID:26375801.

Guerrero, AD, Chu, L, Franke, $T$ et al. Father Involvement Independent variable in Feeding Interactions with Their Young Children. Am J Health Behav, 2016, 40: 221-30. PMID:26931754.

Guldan, GS,Fan, HC,Ma, X,Ni, ZZ,Xiang, X,Tang, MZ. Independent variable Culturally appropriate nutrition education improves infant feeding and growth in rural Sichuan, China. J Nutr. 2000;130:1204. PMID:10801920.

Harvey, H,Coleman, G. Raising healthy eaters: a parenting Study design, age and nutrition curriculum. J Nutr Educ Behav. 2008;40:52.

PMID:18174106.

Harvey-Berino, J, Rourke, J. Obesity prevention in Age preschool native-american children: a pilot study using home visiting. Obes Res, 2003, 11: 606-11.

PMID:12740449.

Hathcock, A, Krause, K, Viera, AJ et al. Satiety Age responsiveness and the relationship between breastfeeding and weight status of toddlers of overweight and obese women. Matern Child Health J, 2014, 18: 1023-30.

PMID:23925718. 
Haycraft, EL, Blissett, JM. Maternal and paternal controlling

feeding practices: reliability and relationships with BMI.

Obesity (Silver Spring), 2008, 16: 1552-8. PMID:18421263.

Herman, A,Nelson, BB,Teutsch, C,Chung, PJ. "Eat Healthy, Independent variable, age Stay Active!": a coordinated intervention to improve nutrition and physical activity among Head Start parents, staff, and children. Am J Health Promot. 2012;27. PMID:22950932.

Hohman, EE, Paul, IM, Birch, LL et al. INSIGHT responsive parenting intervention is associated with healthier patterns of dietary exposures in infants. Obesity (Silver Spring),

Outcome was not growth, size, body composition Comparator not relevant 2017, 25: 185-191. PMID:28008749.

Horodynski, MA,Baker, S,Van,,Olson, B,Brophy-Herb, Dependent variable $\mathrm{H}$,Auld, G. The healthy babies curriculum. J Nutr Educ Behav. 2014;46:151. PMID:24280320.

Hughes, SO, Anderson, CB, Power, TG et al. Measuring Age feeding in low-income African-American and Hispanic parents. Appetite, 2006, 46: 215-23. PMID:16504340.

Hughes, SO, Power, TG, Orlet, et al. Revisiting a neglected Age construct: parenting styles in a child-feeding context.

Appetite, 2005, 44: 83-92. PMID:15604035.

Hughes, SO, Shewchuk, RM, Baskin, ML et al. Indulgent Age feeding style and children's weight status in preschool. J Dev Behav Pediatr, 2008, 29: 403-10. PMID:18714209.

Hundt, GA,Forman, MR. Interfacing anthropology and Independent variable epidemiology: the Bedouin Arab Infant Feeding Study. Soc Sci Med. 1993;36:957. PMID:8480241.

Hurley, KM, Black, MM. Introduction to a supplement on responsive feeding: promoting healthy growth and Study design development for infants and toddlers. J Nutr, 2011, 141. PMID:21270358.

Iacovou, M,Sevilla, A. Infant feeding: the effects of Dependent variable scheduled vs. on-demand feeding on mothers' wellbeing and children's cognitive development. Eur J Public Health. 2013;23:13. PMID:22420982.

Infant feeding practices revisited. Nutrition Committee of the Study design Canadian Paediatric Society. Can Med Assoc J. 1980;122:987-9. PMID:7370888.

Infants in childcare are likely to gain more weight in first year. Nurs Stand, 2008, 23. PMID:27991379.

Karp SM, Lutenbacher M, Dietrich MS. The associations of psychosocial factors and infant feeding beliefs and practices of young, first time, low income mothers. Issues Compr Pediatr Nurs. 2010;33(4):268-87. PubMed PMID: 21047213. 
Karp, SM, Barry, KM, Gesell, SB et al. Parental feeding

patterns and child weight status for Latino preschoolers.

Obes Res Clin Pract, 2014, 8. PMID:24548581.

Kasemsup, R, Reicks, M. The relationship between

Age

maternal child-feeding practices and overweight in Hmong

preschool children. Ethn Dis, 2006, 16: 187-93.

PMID:16599369.

Kaur N., R. Deol, A. Yadav. Correlation of feeding practices Independent variable, age and health profile of children. Nurs J India. 2014;105:128-

30. PMID:25643566.

Koletzko, B, von,. Are there long term protective effects of Study design

breast feeding against later obesity?. Nutr Health, 2001, 15:

225-36. PMID:12003089.

Kong, A,Jones, BL,Fiese, BH,Schiffer, LA,Odoms-Young, Age

A,Kim, Y,Bailey, L,Fitzgibbon, ML. Parent-child mealtime

interactions in racially/ethnically diverse families with

preschool-age children. Eat Behav. 2013;14:451.

PMID:24183134.

Kramer M.S., E. E. Moodie, R. W. Platt. Infant feeding and Independent variable growth: can we answer the causal question?. Epidemiology.

2012;23:790-4. PMID:23038108.

Lapinleimu, H,Viikari, J,Jokinen, E,Salo, P,Routi, T,Leino, Independent variable

A,Ronnemaa, T,Seppanen, R,Valimaki, I,Simell, O.

Prospective randomised trial in 1062 infants of diet low in

saturated fat and cholesterol. Lancet. 1995;345:471.

PMID:7861873.

Lauver, MA, Hizon, L, Bulla, A et al. Infant feeding

Independent variable

practices: the effect on six month weight. J Kans Med Soc,

1981, 82: 403-6. PMID:7288260.

Lee, Y,Birch, LL. Diet quality, nutrient intake, weight status, and feeding environments of girls meeting or exceeding the American Academy of Pediatrics recommendations for total dietary fat. Minerva Pediatr. 2002;54:179. PMID:12070476.

Leonard, CP,D'Augelli, AR,Smiciklas-Wright, H. Effects of a Age weight-control promotion program on parents' responses to family eating situations. J Am Diet Assoc. 1984;84:424.

PMID:6707397.

Letourneau, N. Improving adolescent parent-infant interactions: a pilot study. J Pediatr Nurs. 2001;16:53.

PMID:11247525.

Leung, CY,Miller, AL,Lumeng, JC,Kaciroti, NA,Rosenblum, Age

$\mathrm{KL}$. Maternal representations of their children in relation to feeding beliefs and practices among low-income mothers of young children. Appetite. 2015;95:176. PMID:26145277.

Study design, age

Dependent variable 
Llewellyn, CH,van,,Plomin, R,Fisher, A,Wardle, J. Inherited behavioral susceptibility to adiposity in infancy: a multivariate genetic analysis of appetite and weight in the Gemini birth cohort. Am J Clin Nutr. 2012;95:633.

PMID:22277555.

Lora, KR, Hubbs-Tait, L, Ferris, AM et al. African-American Age and Hispanic children's beverage intake: Differences in associations with desire to drink, fathers' feeding practices, and weight concerns. Appetite, 2016, 107: 558-567.

PMID:27620644.

Ma, JQ, Zhou, LL, Hu, YQ et al. Feeding and growth of normal birth weight infants during the first year of life in Shanghai. Early Hum Dev, 2012, 88: 831-6.

PMID:22749637.

Manios, Y. The 'ToyBox-study' obesity prevention programme in early childhood: an introduction. Obes Rev, 2012, : 1-2. PMID:22309060.

May, AL, Dietz, WH. The Feeding Infants and Toddlers Study 2008: opportunities to assess parental, cultural, and environmental influences on dietary behaviors and obesity prevention among young children. J Am Diet Assoc, 2010, 110. PMID:21092764.

May, M. Nutrition: eat, drink and be healthy. Nurs Mirror. 1980;151:28. PMID:6902319.

Michaliszyn, SF,Sjaarda, LA,Scifres, C,Simhan, $\mathrm{H}$,Arslanian, SA. Maternal excess gestational weight gain and infant waist circumference: a 2-y observational study. Pediatr Res. 2016. PMID:27632776.

Mihrshahi, S, Battistutta, D, Magarey, A et al. Determinants of rapid weight gain during infancy: baseline results from the NOURISH randomised controlled trial. BMC Pediatr, 2011, 11. PMID:22054415.

Mogan, J. Parental weight and its relation to infant feeding patterns and infant obesity. Int J Nurs Stud, 1986, 23: 25564. PMID:3637163.

Moreno, M. Early infant feeding and obesity risk. JAMA Pediatr, 2014, 168. PMID:25365393.

Morgan J. B., P. M. Mumford. A follow-up study of nutrition and anthropometry in pre-school children. Proc Nutr Soc. 1980;39. PMID:7367445.

Morin, KH. Parental style of infant and child feeding: how Study design influential is it?. MCN Am J Matern Child Nurs, 2006, 31.

PMID:17149116.
Independent variable,

Dependent variable

Study design

Study design

Study design

Study design

Independent variable

Study design

Comparator not relevant

Study design

Independent variable, age 
Myers EF., G. H. Johnson. ADAF takes first steps toward

childhood healthy weight initiative. J Am Diet Assoc.

2001;101:588. PMID:11374357.

Navarro, JI, Sigulem, DM, Ferraro, AA et al. The double Independent variable task of preventing malnutrition and overweight: a quasiexperimental community-based trial. BMC Public Health, 2013, 13. PMID:23496939.

Olson, CM, Baker, IR, Demment, MM et al. The healthy Independent variable start partnership: an approach to obesity prevention in young families. Fam Community Health, 2014, 37: 74-85. PMID:24297009.

Oyama, M, Nakamura, K, Tsuchiya, Y et al. Unhealthy Independent variable maternal lifestyle leads to rapid infant weight gain: prevention of future chronic diseases. Tohoku J Exp Med, 2009, 217: 67-72. PMID:19155610.

Passehl, B, McCarroll, C, Buechner, J et al. Preventing Study design childhood obesity: establishing healthy lifestyle habits in the preschool years. J Pediatr Health Care, 2004, 18: 315-9. PMID:15523425.

Patterson, RE, Typpo, JT, Typpo, $\mathrm{MH}$ et al. Factors related Age to obesity in preschool children. J Am Diet Assoc, 1986, 86: 1376-81. PMID:3489748.

Paul, A, Whitehead, R. Infant feeding: the weighting game. Community Outlook. 1986:11. PMID:3637129.

Paul, IM, Williams, JS, Anzman-Frasca, S et al. The Intervention Nurses Start Infants Growing on Healthy Trajectories (INSIGHT) study. BMC Pediatr, 2014, 14. PMID:25037579.

Pelto, GH,Santos, I,Goncalves, H,Victora, C,Martines, J,Habicht, JP. Nutrition counseling training changes physician behavior and improves caregiver knowledge acquisition. J Nutr. 2004;134:357. PMID:14747672.

Perrin, EM,Rothman, RL,Sanders, LM,Skinner, AC,Eden, SK,Shintani, A, Throop, EM,Yin, HS. Racial and ethnic differences associated with feeding- and activity-related behaviors in infants. Pediatrics. 2014;133. PMID:24639273.

Pettman, T,Magarey, A,Mastersson, N,Wilson, A,Dollman, J. Improving weight status in childhood: results from the eat well be active community programs. Int J Public Health. 2014;59:43. PMID:23529384.
Study design, Independent variable

Dependent variable, Study design

Independent variable, Dependent variable
Study design, Dependent variable
Study design, Independent variable 
Power TG, Hughes SO, Goodell LS, Johnson SL, Duran JA, Dependent variable Williams K, Beck AD,

Frankel LA. Feeding practices of low-income mothers: how do they compare to current recommendations? Int J Behav Nutr Phys Act. 2015 Mar 7;12:34. PubMed PMID: 25888909.

Pridham, KF,Schroeder, M,Brown, R,Clark, R. The Independent variable relationship of a mother's working model of feeding to her feeding behaviour. J Adv Nurs. 2001;35:741. PMID:11529976.

Pugliese, MT,Weyman-Daum, M,Moses, N,Lifshitz, F. Independent variable Parental health beliefs as a cause of nonorganic failure to thrive. Pediatrics. 1987;80:175. PMID:3615087.

Qureshi B., J. B. Morgan, A. C. Kimer, D. Donaldson, J. W. Independent variable Dickerson. Feeding practices and birth weights of infants in Southall, Middlesex. J R Soc Health. 1988;108:77-80. PMID:3135398.

Raat, H, Struijk, MK, Remmers, T et al. Primary prevention of overweight in preschool children, the BeeBOFT study Dependent variable, Study (breastfeeding, breakfast daily, outside playing, few sweet drinks, less TV viewing): design of a cluster randomized controlled trial. BMC Public Health, 2013, 13. PMID:24138805.

Rios-Castillo, I, Cerezo, S, Corvalan, C et al. Risk factors Independent variable during the prenatal period and the first year of life associated with overweight in 7-year-old low-income Chilean children. Matern Child Nutr, 2015, 11: 595-605. PMID:23241511.

Robertson, J, Puckering, C, Parkinson, $\mathrm{K}$ et al. Motherchild feeding interactions in children with and without weight Study design faltering; nested case control study. Appetite, 2011, 56: 753-9. PMID:21396417.

Robinson, SM,Marriott, LD,Crozier, SR,Harvey, NC,Gale, Independent variable CR,Inskip, HM,Baird, J,Law, CM,Godfrey, KM,Cooper, C. Variations in infant feeding practice are associated with body composition in childhood: a prospective cohort study. J Clin Endocrinol Metab. 2009;94:2799. PMID:19435826.

Roche, ML,Creed-Kanashiro, HM,Tuesta, I,Kuhnlein, HV. Infant and young child feeding in the Peruvian Amazon: the need to promote exclusive breastfeeding and nutrient-dense traditional complementary foods. Matern Child Nutr. 2011;7:284. PMID:21689271. 
Rodgers, RF, Paxton, SJ, Massey, R et al. Maternal

feeding practices predict weight gain and obesogenic eating

behaviors in young children: a prospective study. Int J

Behav Nutr Phys Act, 2013, 10. PMID:23414332.

Rodgers, RF, Paxton, SJ, McLean, SA et al. Do maternal Age

body dissatisfaction and dietary restraint predict weight gain

in young pre-school children? A 1-year follow-up study.

Appetite, 2013, 67: 30-6. PMID:23541398.

Romeo, S. Transitioning to table foods. The parent offers and the child eats ... sometimes. Adv Nurse Pract. 2001;9.

PMID:12416057.

Rossiter M.D., S. E. Evers. Infant feeding practices and Independent variable children's weight status. Can J Diet Pract Res.

Study design

2013;74:107-13. PMID:24018001.

Ryan, AS,Gussler, JD. Biocultural factors affecting infant Study design feeding and growth. Med Anthropol. 1985;9:93.

PMID:3836323.

Sadler, C. Growing pains. Nurs Stand. 2003;17:16.

Study design

PMID:12640803.

Salariya, EM,Robertson, CM. Relationships between baby Independent variable feeding types and patterns, gut transit time of meconium and the incidence of neonatal jaundice. Midwifery.

1993;9:235. PMID:8283955.

Saltzman, JA, Pineros-Leano, M, Liechty, JM et al. Eating, Dependent variable, Age feeding, and feeling: emotional responsiveness mediates longitudinal associations between maternal binge eating, feeding practices, and child weight. Int J Behav Nutr Phys Act, 2016, 13. PMID:27484590.

Santos I., C. G. Victora, J. Martines, H. Goncalves, D. P. I Independent variable Gigante, N. J. Valle, G. Pelto. Nutrition counseling increases weight gain among Brazilian children. J Nutr. 2001;131:2866-73. PMID:11694610.

Sawley, L. Infant feeding. Nursing (Lond). 1989;3:18. PMID:2761850.

Scheinmann, R,Chiasson, MA,Hartel, D,Rosenberg, TJ. Evaluating a bilingual video to improve infant feeding knowledge and behavior among immigrant Latina mothers. J Community Health. 2010;35:464. PMID:20039195.

Scheiwe, A, Hardy, R, Watt, RG. Four-year follow-up of a Independent variable randomized controlled trial of a social support intervention on infant feeding practices. Matern Child Nutr, 2010, 6: 328-

Study design

37. PMID:21050387. 
Schroeder, N, Rushovich, B, Bartlett, E et al. Early Obesity

Independent variable

Prevention: A Randomized Trial of a Practice-Based

Intervention in 0-24-Month Infants. J Obes, 2015, 2015.

PMID:26078877.

Schwartz, R,Vigo, A,de,,Justo,. The Effect of a Pro-

Independent variable

Breastfeeding and Healthy Complementary Feeding

Intervention Targeting Adolescent Mothers and

Grandmothers on Growth and Prevalence of Overweight of

Preschool Children. PLoS One. 2015;10. PMID:26161657.

Scully H., G. Alberdi, R. Segurado, A. McNamara, K.

Independent variable

Lindsay, M. Horan, E. Hennessy, E. Gibney, F. McAuliffe.

Child Care Exposure Influences Childhood Adiposity at 2

Years: Analysis from the ROLO Study. Child Obes. 2016.

PMID:27854513.

Seal, N,Broome, ME. Prepregnancy Body Mass Index and

Feeding Practices in Relation to Infants' Growth. J Nurse

Study design, Dependent

Pract. 2013;9. PMID:24187528.

Shi, L, Zhang, J, Wang, $Y$ et al. Effectiveness of an variable

educational intervention on complementary feeding

practices and growth in rural China: a cluster randomised

controlled trial. Public Health Nutr, 2010, 13: 556-65.

PMID:19706219.

Skouteris, H, Hill, B, McCabe, M et al. A parent-based

Age

intervention to promote healthy eating and active

behaviours in pre-school children: evaluation of the MEND

2-4 randomized controlled trial. Pediatr Obes, 2016, 11: 4-

10. PMID:25721007.

Souza, SS, Linley, J. Can responsive feeding help to encourage healthy growth?. J Fam Health, 2015, 25: 16-8.

PMID:26749933.

St,, Perumean-Chaney, S, Sigman-Grant, M et al. Family- Study design based interventions for the treatment of childhood obesity. J

Am Diet Assoc, 2002, 102: 640-4. PMID:12008987.

Taitz, LS,Lukmanji, Z. Alterations in feeding patterns and Independent variable rates of weight gain in South Yorkshire infants, 1971-1977. Hum Biol. 1981;53:313. PMID:7309019.

Taveras, EM, Gillman, MW, Kleinman, $\mathrm{K}$ et al. Racial/ethnic differences in early-life risk factors for childhood obesity.

Pediatrics, 2010, 125: 686-95. PMID:20194284.

Taylor, BJ, Heath, AL, Galland, BC et al. Prevention of Study design

Overweight in Infancy (POI.nz) study: a randomised controlled trial of sleep, food and activity interventions for preventing overweight from birth. BMC Public Health, 2011, 11. PMID:22182309.

Independent variable, dependent variable 
Tienboon, P,Wahlqvist, ML, Rutishauser, IH. Early life Independent variable factors affecting body mass index and waist-hip ratio in adolescence. Asia Pac J Clin Nutr. 1992;1:21.

PMID:24323001.

Timby, N, Hernell, O, Lonnerdal, B et al. Parental feeding Study design control in relation to feeding mode and growth pattern during early infancy. Acta Paediatr, 2014, 103: 1072-7. PMID:24948384.

Toddler nutrition: food for thought. Community Pract. 2010;83:20. PMID:20196304.

Townsend, E, Pitchford, NJ. Baby knows best? The impact Age of weaning style on food preferences and body mass index in early childhood in a case-controlled sample. BMJ Open, 2012, 2. PMID:22315302.

Valman, HB. The first year of life: feeding and feeding problems. Br Med J. 1980;280:457. PMID:7189426.

Study design

Vandeweghe, L,Vervoort, L,Verbeken, S,Moens, E,Braet, C. Age Food Approach and Food Avoidance in Young Children: Relation with Reward Sensitivity and Punishment Sensitivity. Front Psychol. 2016;7:928. PMID:27445898.

Ventura, AK,Inamdar, LB,Mennella, JA. Consistency in infants' behavioural signalling of satiation during bottleDependent variable feeding. Pediatr Obes. 2015;10:180. PMID:24990443.

Verbestel, V, De,, Van, et al. Prevention of overweight in Independent variable children younger than 2 years old: a pilot clusterrandomized controlled trial. Public Health Nutr, 2014, 17: 1384-92. PMID:23701835.

Vogels, N, Posthumus, DL, Mariman, EC et al. Independent variable Determinants of overweight in a cohort of Dutch children. Am J Clin Nutr, 2006, 84: 717-24. PMID:17023696.

Watson, PM, Dugdill, L, Pickering, $\mathrm{K}$ et al. Service Independent variable evaluation of the GOALS family-based childhood obesity treatment intervention during the first 3 years of implementation. BMJ Open, 2015, 5. PMID:25652799.

Watt, TT, Appel, L, Roberts, K et al. Sugar, stress, and the Independent variable Supplemental Nutrition Assistance Program: early childhood obesity risks among a clinic-based sample of low-income Hispanics. J Community Health, 2013, 38: 513-20.

PMID:23197136.

Watt, TT,Appel, L,Lopez, V,Flores, B,Lawhon, B. A Primary Independent variable Care-Based Early Childhood Nutrition Intervention:

Evaluation of a Pilot Program Serving Low-Income Hispanic Women. J Racial Ethn Health Disparities. 2015;2:537.

PMID:26863560. 
Wen, LM, Baur, LA, Simpson, JM et al. Effectiveness of

Independent variable

home based early intervention on children's BMI at age 2:

randomised controlled trial. Bmj, 2012, 344.

PMID:22735103.

Wijlaars, LP, Johnson, L, van, et al. Socioeconomic status Independent variable and weight gain in early infancy. Int J Obes (Lond), 2011,

35: 963-70. PMID:21540830.

Winkelstein M. L. Overfeeding in infancy: the early introduction of solid foods. Pediatr Nurs. 1984;10. PMID:6563509.

Wishon P. M., V. G. Kinnick. Helping infants overcome the Study design problem of obesity. MCN Am J Matern Child Nurs. 1986;11:118-21. PMID:3083179.

Woo, JG,Guerrero, ML,Ruiz-Palacios, GM,Peng, Independent variable

YM,Herbers, PM,Yao, W,Ortega, H,Davidson, BS,McMahon, RJ,Morrow, AL. Specific infant feeding practices do not consistently explain variation in anthropometry at age 1 year in urban United States, Mexico, and China cohorts. J Nutr. 2013;143:166.

PMID:23236024.

Wooley, SC, Wooley, OW, Dyrenforth, S. The case against Study design radical interventions. Am J Clin Nutr, 1980, 33: 465-71.

PMID:7355820.

Worobey, J, Pena, J, Ramos, I et al. Infant difficulty and Independent variable early weight gain: does fussing promote overfeeding?.

Matern Child Nutr, 2014, 10: 295-303. PMID:22591002.

Wright P. Development of feeding behaviour in early infancy: implications for obesity. Health Bull (Edinb). 1981;39:197-205. PMID:7251354.

Zhang, J, Himes, JH, Guo, Y et al. Birth weight, growth and Independent variable feeding pattern in early infancy predict overweight/obesity status at two years of age: a birth cohort study of Chinese infants. PLoS One, 2013, 8. PMID:23755127.

Zhang, J, Jiang, J, Himes, JH et al. Determinants of high Independent variable weight gain and high BMI status in the first three months in urban Chinese infants. Am J Hum Biol, 2012, 24: 633-9. PMID:22623279.

Zhang, J, Shi, L, Chen, DF et al. Effectiveness of an Independent variable educational intervention to improve child feeding practices and growth in rural China: updated results at 18 months of age. Matern Child Nutr, 2013, 9: 118-29. PMID:23020102. 